Review

\title{
Evidence-Based Guidelines for Precision Risk Stratifica- tion-Based Screening (PRSBS) for Colorectal Cancer: Lessons Learned from the US Armed Forces: Consensus and Future Directions
}

Itzhak Avital1,2,3,4, Russell C. Langan ${ }^{5}$, Thomas A. Summers 3,6, Scott R. Steele 2,3,7, Scott A. Waldman ${ }^{8}$, Vadim Backman ${ }^{9}$, Judy Yee ${ }^{10}$, Aviram Nissan 3 3,411, Patrick Young ${ }^{12}$, Craig Womeldorph ${ }^{12}$, Paul Mancusco ${ }^{13}$, Renee Mueller13, Khristian Noto13, Warren Grundfest'14, Anton J. Bilchik3,4,15,16,17, Mladjan Protic 3,4,18,19, Martin Daumer ${ }^{4,20}$, John Eberhardt ${ }^{21}$, Yan Gao Man²2, Björn LDM Brücher 1,2,4,23, Alexander Stojadinovic 1,2,3,4,24凶

1. Bon Secours Cancer Institute, Richmond VA

2. Department of Surgery, Uniformed Services University of the Health Sciences, Bethesda, MD

3. United States Military Cancer Institute, Bethesda, MD

4. INCORE, International Consortium of Research Excellence of the Theodor-Billroth-Academy, Munich, Germany

5. Georgetown University Hospital, Washington DC

6. Department of Pathology, Walter Reed National Military Medical Center, Bethesda, MD

7. Department of Surgery, Madigan Army Medical Center, Tacoma, WA

8. Kimmel Cancer Center, Thomas Jefferson University; Department of Pharmacology and Experimental Therapeutics Jefferson Medical College, Philadelphia, PA

9. Department of Biomedical Engineering, Northwestern University, Evanston, IL

10. University of California, San Francisco School of Medicine - Radiology and Biomedical Imaging, San Francisco, CA

11. Department of Surgery, Hadassah Hebrew University Medical Center, Jerusalem, Israel

12. Department of Medicine, Division of Gastroenterology, Walter Reed National Military Medical Center, Bethesda, MD

13. MD Anderson Cancer Center - Orlando, Orlando, FL

14. Telemedicine and Advanced Technology Research Center - West; Food and Drug Administration; University of California- Los Angeles, Los Angeles, CA

15. John Wayne Cancer Institute, Santa Monica, CA

16. Department of Medicine, University of California - Los Angeles, Los Angeles, CA

17. California Oncology Research Center, Los Angeles, CA Diagnostic

18. Clinic of Abdominal, Endocrine, and Transplantation Surgery, Clinical Center of Vojvodina, Novi Sad, Serbia

19. University of Novi Sad - Medical Faculty, Novi Sad, Serbia

20. Sylvia Lawry Center for MS Research, Munich, Germany

21. DecisionQ Corporation, Washington, D.C.

22. Diagnostic and Translational Research Center, Henry Jackson Foundation for the Advancement of Military Medicine, Gaithersburg, MD

23. Theodor-Billroth-Academy, Munich, Germany

24. Department of Surgery, Division of Surgical Oncology, Walter Reed National Military Medical Center, Bethesda, MD

$\triangle$ Corresponding author: Alexander Stojadinovic, MD FACS, Walter Reed National Military Medical Center, 8901 Wisconsin Avenue, Bldg. 9, Room 1272, Bethesda, MD 20889. Stojadinovicmd2011@gmail.com

() Ivyspring International Publisher. This is an open-access article distributed under the terms of the Creative Commons License (http://creativecommons.org/ licenses/by-nc-nd/3.0/). Reproduction is permitted for personal, noncommercial use, provided that the article is in whole, unmodified, and properly cited.

Received: 2013.01.08; Accepted: 2013.02.01; Published: 2013.03.0I

\begin{abstract}
Colorectal cancer (CRC) is the third most common cause of cancer-related death in the United States (U.S.), with estimates of 143,460 new cases and 51,690 deaths for the year 2012. Numerous organizations have published guidelines for CRC screening; however, these numerical estimates of incidence and disease-specific mortality have remained stable from years prior. Technological, genetic profiling, molecular and surgical advances in our modern era should allow us to improve
\end{abstract}


risk stratification of patients with CRC and identify those who may benefit from preventive measures, early aggressive treatment, alternative treatment strategies, and/or frequent surveillance for the early detection of disease recurrence. To better negotiate future economic constraints and enhance patient outcomes, ultimately, we propose to apply the principals of personalized and precise cancer care to risk-stratify patients for CRC screening (Precision Risk Stratification-Based Screening, PRSBS). We believe that genetic, molecular, ethnic and socioeconomic disparities impact oncological outcomes in general, those related to CRC, in particular. This document highlights evidence-based screening recommendations and risk stratification methods in response to our CRC working group private-public consensus meeting held in March 2012. Our aim was to address how we could improve CRC risk stratification-based screening, and to provide a vision for the future to achieving superior survival rates for patients diagnosed with CRC.

Key words: cancer screening, risk identification, colon, rectal, colorectal cancer, evidence-based medicine, consensus

\section{Introduction}

Colorectal cancer (CRC) is the $3^{\text {rd }}$ most common cause of cancer-related mortality in the US [1]. Approximately one out of every four patients presenting with conventionally staged node-negative disease [American Joint Committee on Cancer (AJCC) Stage I and II], and over $50 \%$ of patients with node-positive, non-metastatic (AJCC Stage III) disease will develop local recurrence and/or distant metastases [2, 3]. Across all CRC stages, approximately $30 \%$ of patients will develop distant metastases and once metastases ensue, prognosis is decidedly poor, and treatment largely palliative in nature [2].

Current theory suggests the progression from normal colonic mucosa to invasive carcinoma occurs over a period of 4-10 years [4]. This crucial window therefore represents an ideal opportunity to exploit screening modalities based on risk stratification methods in an attempt to improve overall survival through early definitive therapeutic intervention. This concept is well established in epithelial malignancies, specifically; definitive therapeutic intervention early in the natural history of cancer is associated with optimal overall survival benefit. Hence, the goal is to optimize oncological benefit when the disease is in its pre-malignant phases or in its earliest node-negative cancer stage.

If implemented appropriately Precision Risk Stratification-Based Screening, PRSBC, would: 1. Spare low-risk patients likely cured by surgery alone the toxicity of systemic therapy; 2. Identify and treat at-risk patients with early stage CRC; and, 3. Limit treatments to patients with clinically latent or stable residual disease, thereby reserving additional therapy for treatment-responsive disease progression at a later time in the course of disease [5]. Moreover, as nearly all pre-malignant colon lesions would eventually progress to malignant ones, we would like to suggest that the most important impact of risk stratification or screening would be: the identification of pre-malignant lesions or early CRC that can be locally excised or treated, which would significantly reduce the incidence of $\mathrm{CRC}$, and treatment-related impact on patient quality of life (QOL) and healthcare-related costs.

Technological, genetic, molecular, and surgical advances in our modern era should allow us to accurately risk stratify patients who may benefit from early (preventive or) definitive therapy, alternative treatment strategies, and/or frequent surveillance for the early detection of disease recurrence. We believe that genetic, molecular, ethnic and socioeconomic disparities impact oncologic outcomes in CRC; therefore, clinical decision support systems (CDSS) and treatment algorithms must expand beyond the current/traditional AJCC tumor stage criteria that don't take into account factors that underlie these disparities. Herein, we will discuss relevant literature pertaining to screening based on risk stratification in CRC (Precision Risk Stratification-Based Screening, PRSBS) and we suggest methods to improve these facets of risk stratification, screening and early detection in oncology, with the potential for efficacious and cost-effective therapy leading to improved overall QOL and survival.

When one considers CRC screening, much can be learned from the United States Military Health System (MHS). The MHS provides a unique setting to study oncologic outcomes, as it includes a large, relatively young group of individuals who are genetically, molecularly, ethnically and economically diverse, and have equal access to free, population-based health care. Currently, CRC screening remains under-utilized by the American civilian population, as it is estimated that $\sim 60 \%$ of CRC deaths could be prevented if all individuals over the age of 50 years underwent regular recommended screening [6]. This 
fact, in and of itself, represents a significant opportunity to transform cancer screening and care through population-based initiatives of outreach, education and stimulus aimed at improving compliance with recommended CRC screening, and reducing cancer-specific mortality. In contrast to the civilian population, it has been found that, in the US military equal access healthcare system, more patients were current or compliant with national CRC screening guidelines $(71 \%$ vs. $52-59 \%, \mathrm{P}<0.05)$ [7].

The US military population also differs from the US civilian population in its exposure to cancer risk factors (sun exposure during out-of-country deployments, for example) and access (free- and equal) to medical care [8]. Zhu et al. studied four common cancers amongst the US population (CRC, lung, prostate and breast cancer) and compared the incidence of these cancers as well as two common malignancies in young adults (cervical and testicular cancer) amongst the military and civilian populations [8]. Interestingly, incidence rates were significantly lower in the military population for CRC amongst aged-adjusted Caucasian men for ages 20-59 years [8]. These results suggest that cancer patterns may differ between US military and civilian populations [8]. This may be explained by differences in exposure to risk factors such as physical fitness, tobacco use, alcohol consumption, diet, and sunlight exposure [8]. However, compared with the general population, the military populations are more likely to undergo cancer screening and surveillance because military members have free and equal access to health care (i.e. relatively fewer health disparities), and active duty members undergo directed health promotion, disease prevention and screening initiatives [8].

The rate of CRC screening compliance among the civilian population, using current national guidelines, is quite low, with only $5 \%$ to $60 \%$ of insured patients achieving adequate screening [8]. Screening compliance rates are even lower rates in uninsured and minority patient populations [8]. The elucidation of differences in cancer incidence patterns between the military and civilian populations may lead to a better understanding of etiology, and the development of preventive strategies specific to each population, based on unique population-based characteristics and disease-related risk factors [8]. Until more effective therapies can be developed, one strategy for improving outcomes while reducing the socio-economic burden of CRC is to follow current US military CRC early detection initiatives that have demonstrated unparalleled success in population compliance with screening. Another key strategic effort will be to develop novel strategies for CRC Preci- sion Risk Stratification-Based Screening that will not only further increase rates of screening compliance, but also facilitate detection of CRC in its earliest stages, and ultimately translate into life and personal and health system cost savings.

Pertinent questions regarding CRC risk stratification, screening and oncological outcomes remain to be answered: 1. In particular, what is the effect of a PRSBS and precision medicine cancer care strategy, an approach which applies predictive and prognostic biomarkers and patient-specific attributes using a 'personalized lifespan approach'? This strategy takes into consideration factors such as ethnicity, socioeconomic status, insurance status, tumor biology, genetic profiling, molecular milieu, among others, and their impact on oncological outcome, independent of disease stage will need to be defined. 2. Why do node negative colon cancers recur? 3 . Why is disease-free survival so variable amongst patients with CRC? 4. Which patients with CRC will benefit from adjuvant systemic therapy? 5 . Which patients are likely to suffer from the risks of systemic therapy for little or no therapeutic gain? [9] We will review current CRC screening guidelines, discuss current and novel modalities of screening, and discuss relevant literature pertaining to CRC risk stratification, and the use of Clinical Decision Support Systems for risk assessment as means of improving CRC outcomes. With the primary aim of better negotiating future economic constraints pursuant to enhanced patient outcomes, we apply the principles of precision risk stratification-based screening in an effort to advance a vision to achieving superior survival rates for patients diagnosed with CRC.

\section{Screening Guidelines}

One of the basic problems pertaining to CRC screening is that, to date, there is not one clear agreed-upon, unified approach to CRC screening, as a number of national organizations and professional societies provide clinical practice guidelines (CPGs) for the care and prevention of CRC. For instance, the United States Preventive Services Task Force (USPSTF), American College of Gastroenterology (ACG) and the American Cancer Society (ACS) - US Multi-Society Task Force (MSTF) each has its own set of guidelines Table 1. Published in 2008, the USPSTF recommended CRC screening that involved a combination of stool-based laboratory studies and direct visualization of the colonic mucosa $[10,11]$. Beginning at the age of 50 and continuing to age 75 , it recommended fecal occult blood testing (FOBT) yearly, sigmoidoscopy every 5 years, or colonoscopy every 10 years [11]. The USPSTF also recommended against 
routine screening for CRC in adults 76 to 85 years of age; however, it deemed that certain unique considerations for patients on a case-by-case basis may support its use [11]. For those greater than 85 years of age the USPSTF recommended against screening altogether [11]. As for computed tomography (CT) colonography and fecal DNA testing, the USPSTF concluded that there was insufficient evidence to recommend these methods as CRC screening modalities [11]. In addition, the USPSTF commented that the rate of CRC was higher in African American males; however, it stated that these recommendations were intended to generally apply to all racial and ethnic groups [11].

The American Cancer Society - US Multi-Society Task Force on CRC (ACS-MSTF) and the American College of Radiology (ACR) jointly published guidelines for asymptomatic average risk adults, which utilized screening options, allowing patients and physicians the ability to tailor screening methods in the hopes of improving the percentage of Americans screened (Table 2). The ACS-MSTF and ACR also grouped CRC screening tests into cancer prevention and cancer detection tests [12]. Cancer prevention tests were those which could image both cancer and polyps, whereas cancer detection tests had low sensitivity for polyps and typically lower sensitivity for cancer detection compared with that of cancer prevention tests [13]. The ACS-MSTF concluded somewhat nebulously that clinicians should make patients aware of the full range of screening options, but at a minimum should offer patients a choice between a screening test that primarily is effective at early cancer detection and a screening test that is effective at both early cancer detection and cancer prevention through the detection and removal of polyps [13].

Table I: Most commonly used screening and risk stratification systems

\begin{tabular}{llll}
\hline & USPSTF & ACG & ACS-MSTF \\
\hline Beginning age & 50 & $50(45$ for African Americans) & 50 \\
Continuing to age & 75 & $\mathrm{n} / \mathrm{a}$ & $\mathrm{n} / \mathrm{a}$ \\
Not for routine & $76-85$ & $\mathrm{n} / \mathrm{a}$ & $\mathrm{n} / \mathrm{a}$ \\
Stopping age & $>85$ & $\mathrm{n} / \mathrm{a}$ & $\mathrm{n} / \mathrm{a}$ \\
Recommended Methodologies & gFOBT or FIT, annually & gFOBT or FIT, annually & FOBT annually or \\
& FSIG, every 5years & FSIG, every 5-10 years, & FIT annually or \\
& or COL, every 10 years & or CTC every 5 years & FSIG every 5 years or \\
& DCBE, every 5years & & COL every 10 or years or \\
& & & DCBE every 5 years or \\
& & & CTC every 5 years or \\
sDNA (interval uncertain)
\end{tabular}

Not recommended methodologies sDNA

CTC

USPSTF: United States Preventive Services Task Force; ACG: American College of Gastroenterology; AS-MSTF: American Cancer Society - US Multi-Society Task Force; DOD: Department of Defense; FSIG: Flexible sigmoidoscopy (FS); COL: Colonoscopy; FOBT: Fecal occult blood test; FIT: fecal immunochemical test sDNA: Stool DNA test; CTC: CT colonography; DCBE: Double-contrast barium enema.

Table 2: The American Cancer Society - US Multi-Society Task Force on CRC (ACS-MSTF) and the American College of Radiology (ACR) surveillance guidelines according to risk groups defined by colonoscopic findings

\begin{tabular}{|c|c|}
\hline Risk groups based on colonoscopy findings & $\begin{array}{l}\text { Surveillance recom- } \\
\text { mendations }\end{array}$ \\
\hline Patients with only one or two small $(<1 \mathrm{~cm})$ tubular adenomas with only low-grade dysplasia (low-risk subjects) & $5-10$ years \\
\hline $\begin{array}{l}\text { Patients with } 3 \text { to } 10 \text { adenomas, or any adenoma }>1 \mathrm{~cm} \text {, or any adenoma with villous features, or high-grade } \\
\text { dysplasia (high-risk subjects) }\end{array}$ & 3 years \\
\hline $\begin{array}{l}\text { High risk subjects with follow-up endoscopy showing normal findings or presence of only one or two small }(<1 \\
\mathrm{cm}) \text { tubular adenomas with only low-grade dysplasia }\end{array}$ & 5 years \\
\hline Patients who have more than 10 adenomas at one examination* & $<3$ years \\
\hline Patients with sessile adenomas that are removed piecemeal & 2-6 months \\
\hline Patients with small rectal hyperplastic polyps & $\begin{array}{l}\text { No follow-up indica- } \\
\text { tion }\end{array}$ \\
\hline
\end{tabular}


The American College of Gastroenterology supported the division of screening tests into cancer prevention and cancer detection modalities and released formal screening guidelines in 2008 [13]. This emphasis by the ACG reflects consideration of other $\mathrm{CRC}$ risk factors such as evidence-based associations between obesity / Metabolic Syndrome - related risk factors and the development of CRC. Cancer prevention tests should be offered first and the preferred CRC prevention test was colonoscopy every 10 years, beginning at age 50 (according to the ACG screening should begin at age 45 years in African Americans, Table 1) [13]. Alternative CRC prevention tests include flexible sigmoidoscopy every 5-10 years (based on data that $58 \%$ of CRC are located distally in the colon and within reach of the sigmoidoscope) and CT colonography (Virtual Colonoscopy) every 5 years $[13,14]$. Cancer detection tests should be offered to patients who declined colonoscopy or another cancer prevention test [13]. The preferred cancer detection test was annual fecal immunochemical testing (FIT) for blood [13]. Alternative cancer detection tests were annual FOBT (Hemoccult Sense Test) or stool DNA (sDNA) testing every 3 years (Table 1) [13].

The main contents of these various screening recommendations are summarized in Table $\mathbf{1}$. As is readily apparent, we as a medical community continue to have difference of opinion, frankly we struggle to determine the safest, most efficient and efficacious CRC screening algorithm. Considering the future economic environment, it will be advantageous to identify patients who need not be screened based on stratification to low-risk stratum by novel, cost-effective, accurate, less frequent, and readily accessible methods than are currently in widespread use. In brief, we must utilize alternative strategies such as novel screening methods, biomarkers and risk stratification approaches (PRSBC) in order to reduce costs and improve overall outcomes.

\section{Current Screening Modalities}

The sequence of progression from colorectal adenoma to invasive carcinoma in $\mathrm{CRC}$, along with the accessibility of the colon and rectum to endoscopic imaging has led to the development of screening protocols based on direct imaging of the colorectal mucosa [15]. Currently, colonoscopic examination is the standard of practice for effective cancer screening [16]. Capsule endoscopy has been evaluated as another possible indirect method of visualizing the colonic mucosa, but it also lacks adequate cancer detection sensitivity ( $\mathrm{Sn}=74 \%, 95 \% \mathrm{CI}: 52-88 \%)$ to be used as a screening test [17]. The isolation of stool DNA (sDNA), derived from sloughed mucosa and poten- tially from pre-malignant and CRC cells, and the subsequent identification of CRC-associated genetic mutations in stool samples have been described [18]. DNA amplification techniques have improved the nucleic acid yield in stool samples [19], opening the possibility for screening of specific genetic mutations associated with CRC. A commercial test has been developed, which detects $\mathrm{k}$-ras, APC, and p53 gene mutations, along with long DNA and the microsatellite instability (MSI) marker, BAT-26. A blinded comparison of fecal DNA vs. Hemoccult II testing found that fecal DNA detected 16 of 31 invasive cancers versus 4 of 31 in the Hemoccult II group (52\% vs. $13 \% ; \mathrm{P}=0.003$ ) [17]. Specificity in patients with negative findings on colonoscopy was similar in both tests (Sp: Fecal DNA $=94 \%$; Hemoccult II $=95 \%$. The key underlying message is that the DNA-based test showed sensitivity for advanced adenomas and invasive carcinoma of only 52\% [20]. Shown in Table 3 are the estimated costs and life years gained with established screening approaches currently in use as compared to no screening for CRC. The cost effectiveness analysis of newer CRC screening tests (fecal immunochemical test, stool DNA, computed tomographic colonography) compared with established screening tests (FOBT, flexible sigmoidoscopy, optical colonoscopy) is shown in Table 4.

The gold standard for CRC screening remains direct colonic visualization with optical colonoscopy ( $\mathrm{Sn}=96 \%, 87 \%$ and $77 \%$ for the detection of polyps sized $\geq 10 \mathrm{~mm}, 6-9 \mathrm{~mm}$ and $<6 \mathrm{~mm}$ in size, respectively) [21]. In a case-controlled comparison of patients undergoing colonoscopy versus historical control patients who did not undergo screening, the use of colonoscopy reduced mortality risk, with an odds ratio (OR) of 0.41 [22]. Given the invasive nature of direct colonic visualization, indirect methods of evaluating the colonic mucosa have been developed. Double-contrast barium enema (DCBE) involves radiographic imaging of the colon following the instillation of barium, which is then followed by distension of the colon with air. This modality is associated with unacceptably high false negative rates (especially for polyps $<1 \mathrm{~cm}$ in size) to be recommended as a valid, clinically relevant screening evaluation [23]. Sensitivity of DCBE was $83 \%$ versus $95 \%$ associated with optical colonoscopy [24]. However, virtual colonoscopy (VC) or computed tomographic (CT) colonography has gained popularity as a safe and accurate alternative to standard optical colonoscopy [6]. VC/CT colonography involves thin-slice reconstruction of the colon for cross-sectional and three-dimensional (3-D) reconstruction radiographic evaluation of the mucosa. Prior to the scan, standard oral bowel preparation is 
administered in addition to CT barium sulfate along with diatrizoate meglumine and diatrizoate sulfate for stool tagging [6]. Images are then obtained in the su- pine and prone positions with automated rectal insufflation of carbon dioxide $\left(\mathrm{CO}_{2}\right)$ for colonic distension [6].

Table 3. Discounted Life-years Gained, Costs, and Costs per Life-year Gained of Established Screening Strategies for Colorectal Cancer Compared With no Screening. Source: Iris Lansdorp-Vogelaar, Amy B. Knudsen and Hermann Brenner. Cost-effectiveness of Colorectal Cancer Screening. Epidemiol Rev (20II) 33 (I): 88-100.

\begin{tabular}{|c|c|c|c|c|c|c|c|c|c|c|c|c|c|c|c|}
\hline \multirow{2}{*}{$\begin{array}{l}\text { Study: First } \\
\text { Author, Year } \\
\text { (Reference } \\
\text { No.) })^{\mathrm{a}}\end{array}$} & \multicolumn{3}{|c|}{ Annual gFOBT } & \multicolumn{3}{|c|}{ Biennial gFOBT } & \multicolumn{3}{|c|}{$\begin{array}{l}\text { Flexible Sigmoidoscopy } \\
\text { Every } 5 \text { Years }\end{array}$} & \multicolumn{3}{|c|}{$\begin{array}{l}\text { Flexible Sigmoidoscopy } \\
\text { Every } 5 \text { Years + Annual } \\
\text { gFOBT }\end{array}$} & \multicolumn{3}{|c|}{$\begin{array}{l}\text { Colonoscopy Every } 10 \\
\text { Years }\end{array}$} \\
\hline & LYG & Cost & $\begin{array}{l}\text { Cost/ } \\
\text { LYG }\end{array}$ & LYG & Cost & Cost/LYG & LYG & Cost & Cost/LYG & LYG & Cost & Cost/LYG & LYG & Cost & $\begin{array}{l}\text { Cost/ } \\
\text { LYG }\end{array}$ \\
\hline $\begin{array}{l}\text { Flanagan, } \\
2003(34)\end{array}$ & 0.025 & 328 & 13,100 & 0.016 & 185 & 11,600 & & & & & & & & & \\
\hline $\begin{array}{l}\text { Frazier, } 2000 \\
\text { (35) }\end{array}$ & 0.042 & 825 & 19,600 & & & & 0.039 & 751 & 19,500 & 0.059 & 1,523 & 26,000 & 0.048 & 1,514 & 31,700 \\
\hline $\begin{array}{l}\text { Gyrd-Hansen, } \\
1998 \text { (28) }\end{array}$ & 0.006 & 36 & 6,400 & 0.004 & 20 & 5,300 & & & & & & & & & \\
\hline $\begin{array}{l}\text { Hassan, } 2007 \\
(44)\end{array}$ & & & & & & & & & & & & & 0.036 & -10 & CS \\
\hline $\begin{array}{l}\text { Helm, } 2000 \\
\text { (36) }\end{array}$ & & & & 0.014 & 72 & 4,000 & & & & & & & & & \\
\hline $\begin{array}{l}\text { Khandker, } \\
2000 \text { (37) }\end{array}$ & 0.100 & 2,519 & 25,600 & & & & 0.090 & 1,904 & 22,500 & 0.110 & 3,553 & 32,400 & 0.110 & 3,487 & 31,500 \\
\hline $\begin{array}{l}\text { Lejeune, } 2004 \\
\text { (38) }\end{array}$ & & & & 0.029 & 126 & 4,400 & & & & & & & & & \\
\hline $\begin{array}{l}\text { Leshno, } 2003 \\
\text { (39) }\end{array}$ & 0.160 & -158 & CS & & & & & & & 0.182 & -324 & CS & 0.180 & -26 & CS \\
\hline $\begin{array}{l}\text { Macafee, } 2008 \\
(45)\end{array}$ & & & & 0.009 & 30 & 3,400 & & & & & & & & & \\
\hline $\begin{array}{l}\text { O'Leary, } 2004 \\
(40)\end{array}$ & & & & & & & & & & & & & 0.021 & 2,883 & 9,800 \\
\hline $\begin{array}{l}\text { Pickhardt, } \\
2007 \text { (19) }\end{array}$ & & & & & & & & & & & & & 0.046 & 495 & 10,700 \\
\hline $\begin{array}{l}\text { Shimbo, } 1994 \\
\text { (32) }\end{array}$ & 0.013 & 750 & 56,300 & & & & & & & & & & & & \\
\hline $\begin{array}{l}\text { Song, } 2004 \\
\text { (20) }\end{array}$ & 0.056 & 508 & 9,100 & & & & 0.048 & 940 & 19,600 & 0.063 & 1,347 & 21,500 & 0.062 & 1,330 & 21,500 \\
\hline $\begin{array}{l}\text { Sonnenberg, } \\
2000(41)\end{array}$ & 0.019 & 285 & 15,100 & & & & 0.036 & 2,059 & 56,600 & & & & 0.080 & 1,355 & 17,000 \\
\hline $\begin{array}{l}\text { Steele, } 2004 \\
(42)\end{array}$ & 0.008 & 94 & 11,700 & & & & 0.012 & 132 & 11,400 & & & & 0.019 & 515 & 26,800 \\
\hline $\begin{array}{l}\text { Stone, } 2004 \\
\text { (27) }\end{array}$ & & & & 0.001 & 23 & 15,500 & & & & & & & & & \\
\hline $\begin{array}{l}\text { Tappenden, } \\
2007 \text { (26) }\end{array}$ & & & & 0.026 & 147 & 5,700 & & & & & & & & & \\
\hline Tsoi, 2008 (46) & 0.094 & 651 & 7,000 & & & & 0.110 & 989 & 9,000 & & & & 0.159 & 1,281 & 8,100 \\
\hline $\begin{array}{l}\text { Vijan, } 2007 \\
(23)\end{array}$ & 0.029 & 202 & 6,800 & & & & 0.031 & 948 & 30,100 & 0.050 & 1,138 & 22,800 & 0.053 & 544 & 10,200 \\
\hline $\begin{array}{l}\text { Wagner, } 1995 \\
\text { (18) }\end{array}$ & 0.059 & 1,086 & 18,500 & & & & 0.036 & 705 & 19,700 & 0.067 & 1,461 & 21,700 & 0.059 & 1,028 & 17,300 \\
\hline $\begin{array}{l}\text { Whynes, } 1998 \\
\text { (25) }\end{array}$ & & & & 0.017 & 76 & 4,600 & & & & & & & & & \\
\hline Wu, 2006 (47) & 0.025 & -27 & CS & & & & 0.014 & 35 & 2,500 & & & & 0.025 & -2 & CS \\
\hline $\begin{array}{l}\text { Zauber } \\
\text { (MISCAN), } \\
2009 \text { (22) }\end{array}$ & 0.066 & -88 & CS & & & & 0.077 & 102 & 1,300 & 0.085 & 133 & 1,600 & 0.087 & 205 & 2,400 \\
\hline
\end{tabular}




\begin{tabular}{|c|c|c|c|c|c|c|c|c|c|c|c|c|c|c|}
\hline \multirow{2}{*}{$\begin{array}{l}\text { Study: First } \\
\text { Author, Year } \\
\text { (Reference } \\
\text { No.)a }\end{array}$} & \multicolumn{3}{|c|}{ Annual gFOBT } & \multicolumn{3}{|c|}{ Biennial gFOBT } & \multicolumn{2}{|c|}{$\begin{array}{l}\text { Flexible Sigmoidoscopy } \\
\text { Every } 5 \text { Years }\end{array}$} & \multicolumn{3}{|c|}{$\begin{array}{l}\text { Flexible Sigmoidoscopy } \\
\text { Every } 5 \text { Years + Annual } \\
\text { gFOBT }\end{array}$} & \multicolumn{3}{|c|}{$\begin{array}{l}\text { Colonoscopy Every } 10 \\
\text { Years }\end{array}$} \\
\hline & LYG & Cost & $\begin{array}{l}\text { Cost/ } \\
\text { LYG }\end{array}$ & LYG & Cost & Cost/LYG LYG & Cost & Cost/LYG & LYG & Cost & Cost/LYG & LYG & Cost & $\begin{array}{l}\text { Cost/ } \\
\text { LYG }\end{array}$ \\
\hline $\begin{array}{l}\text { Zauber } \\
\text { (SimCRC), } \\
2009(22)\end{array}$ & 0.060 & -305 & CS & & & 0.069 & -231 & CS & 0.087 & -315 & CS & 0.094 & -207 & CS \\
\hline $\begin{array}{l}\text { Zauber } \\
\text { (CRC-SPIN), } \\
2009(22)\end{array}$ & 0.064 & -471 & CS & & & 0.080 & -375 & CS & 0.095 & -413 & CS & 0.106 & -403 & CS \\
\hline
\end{tabular}

Table 4. (Incremental) Cost-effectiveness of Newly Developed Colorectal Cancer Screening Strategies Compared With no Screening and With Established Tests. Source: Iris Lansdorp-Vogelaar, Amy B. Knudsen and Hermann Brenner. Cost-effectiveness of Colorectal Cancer Screening. Epidemiol Rev (20II) 33 (I): 88-100

\begin{tabular}{|c|c|c|c|c|c|c|}
\hline $\begin{array}{l}\text { Strategy and Study: } \\
\text { First Author, Year } \\
\text { (Reference No.)a }\end{array}$ & & Study Details & & $\begin{array}{l}\text { Comparator Strate- } \\
\text { gies }\end{array}$ & CER므 & ICER \\
\hline FIT & Test Used & $\begin{array}{l}\text { Sensitivity for } \\
\text { Cancer, Speci- } \\
\text { ficity }\end{array}$ & $\begin{array}{l}\text { Test } \\
\text { Costs } \underline{\underline{b}}\end{array}$ & & & \\
\hline Berchi, 2004 (33) & Magstream & $\begin{array}{l}\text { Sn: } 82 \\
\text { Sp: } 96\end{array}$ & 12 & gFOBT & & 3,900 \\
\hline Chen, 2007 (43) & OC-SENSOR & $\begin{array}{l}\text { Sn: } 64.6-84.6 \\
\text { Sp: } 77.1-97.1\end{array}$ & 3 & No screening & CS & Dominant \\
\hline Parekh, 2008 (49) & Insure FIT & $\begin{array}{l}\text { Sn: } 76 \\
\text { Sp: } 91\end{array}$ & 25 & $\begin{array}{l}\text { gFOBT, COL, stool } \\
\text { DNA test }\end{array}$ & CS & Dominant \\
\hline Shimbo, 1994 (32) & $\begin{array}{l}\text { Reversed passive he- } \\
\text { magglutination assay }\end{array}$ & $\begin{array}{l}\text { Sn: } 48.1-84.3 \\
\text { Sp: } 99\end{array}$ & 13 & gFOBT & 25,900 & Dominant \\
\hline $\begin{array}{l}\text { Zauber, } 2009 \text { (MISCAN) } \\
(22)\end{array}$ & Mix of tests & $\begin{array}{l}\text { Sn: } 70 \\
\text { Sp: } 95\end{array}$ & 24 & $\begin{array}{l}\text { gFOBT, SENSA, } \\
\text { COL, FSIG, CTC, } \\
\text { FSIG + gFOBT }\end{array}$ & 800 & $\begin{array}{l}\text { Dominated by } \\
\text { SENSA }\end{array}$ \\
\hline $\begin{array}{l}\text { Zauber, } 2009 \text { (SimCRC) } \\
\text { (22) }\end{array}$ & Mix of tests & $\begin{array}{l}\text { Sn: } 70 \\
\text { Sp: } 95\end{array}$ & 24 & $\begin{array}{l}\text { gFOBT, SENSA, } \\
\text { COL, FSIG, CTC, } \\
\text { FSIG + gFOBT }\end{array}$ & CS & $\begin{array}{l}\text { Dominated by } \\
\text { SENSA }\end{array}$ \\
\hline $\begin{array}{l}\text { Zauber, } 2009 \\
\text { (CRC-SPIN) (22) }\end{array}$ & Mix of tests & $\begin{array}{l}\text { Sn: } 70 \\
\text { Sp: } 95\end{array}$ & 24 & $\begin{array}{l}\text { gFOBT, SENSA, } \\
\text { COL, FSIG, CTC, } \\
\text { FSIG + gFOBT }\end{array}$ & CS & $\begin{array}{l}\text { Dominated by } \\
\text { SENSA }\end{array}$ \\
\hline Stool DNA & Test Used & $\begin{array}{l}\text { Sensitivity for } \\
\text { Cancer, Speci- } \\
\text { ficity }\end{array}$ & $\begin{array}{l}\text { Test } \\
\text { Costs } \underline{\mathrm{b}}\end{array}$ & & & \\
\hline Leshno, 2003 (39) & PreGen-Plus & $\begin{array}{l}\text { Sn: } 91 \\
\text { Sp: } 90\end{array}$ & 86 & $\begin{array}{l}\text { gFOBT, COL, FSIG + } \\
\text { gFOBT }\end{array}$ & 600 & $\begin{array}{l}\text { Dominated by COL } \\
\text { and FSIG }+ \text { gFOBT }\end{array}$ \\
\hline Parekh, 2008 (49) & PreGen-Plus & $\begin{array}{l}\text { Sn: } 65 \\
\text { Sp: } 95\end{array}$ & 879 & gFOBT, COL, FIT & $17,500-23,700$ & $\begin{array}{l}\text { Dominated by all } \\
\text { tests }\end{array}$ \\
\hline Wu, 2006 (47) & PreGen-Plus & $\begin{array}{l}\text { Sn: } 52 \\
\text { Sp: } 94\end{array}$ & 53 & gFOBT, FSIG, COL & $9,300-11,900$ & $\begin{array}{l}\text { Dominated by all } \\
\text { tests }\end{array}$ \\
\hline $\begin{array}{l}\text { Zauber (MISCAN), } 2007 \\
\text { (52) }\end{array}$ & PreGen-Plus & $\begin{array}{l}\text { Sn: } 70 \\
\text { Sp: } 96\end{array}$ & 375 & $\begin{array}{l}\text { gFOBT, SENSA, } \\
\text { COL, FSIG, FIT, FSIG } \\
+ \text { gFOBT }\end{array}$ & $12,200-23,900$ & $\begin{array}{l}\text { Dominated by all } \\
\text { tests }\end{array}$ \\
\hline $\begin{array}{l}\text { Zauber (SimCRC), } 2007 \\
\text { (52) }\end{array}$ & PreGen-Plus & $\begin{array}{l}\text { Sn: } 70 \\
\text { Sp: } 96\end{array}$ & 375 & $\begin{array}{l}\text { gFOBT, SENSA, } \\
\text { COL, FSIG, FIT, FSIG } \\
+ \text { gFOBT }\end{array}$ & $10,800-31,800$ & $\begin{array}{l}\text { Dominated by all } \\
\text { tests }\end{array}$ \\
\hline СТС & Follow-up Interval & $\begin{array}{l}\text { Sensitivity for } \\
\text { Cancer, Speci- } \\
\text { ficity }\end{array}$ & $\begin{array}{l}\text { Test } \\
\text { Costs } \underline{\underline{b}}\end{array}$ & & & \\
\hline
\end{tabular}




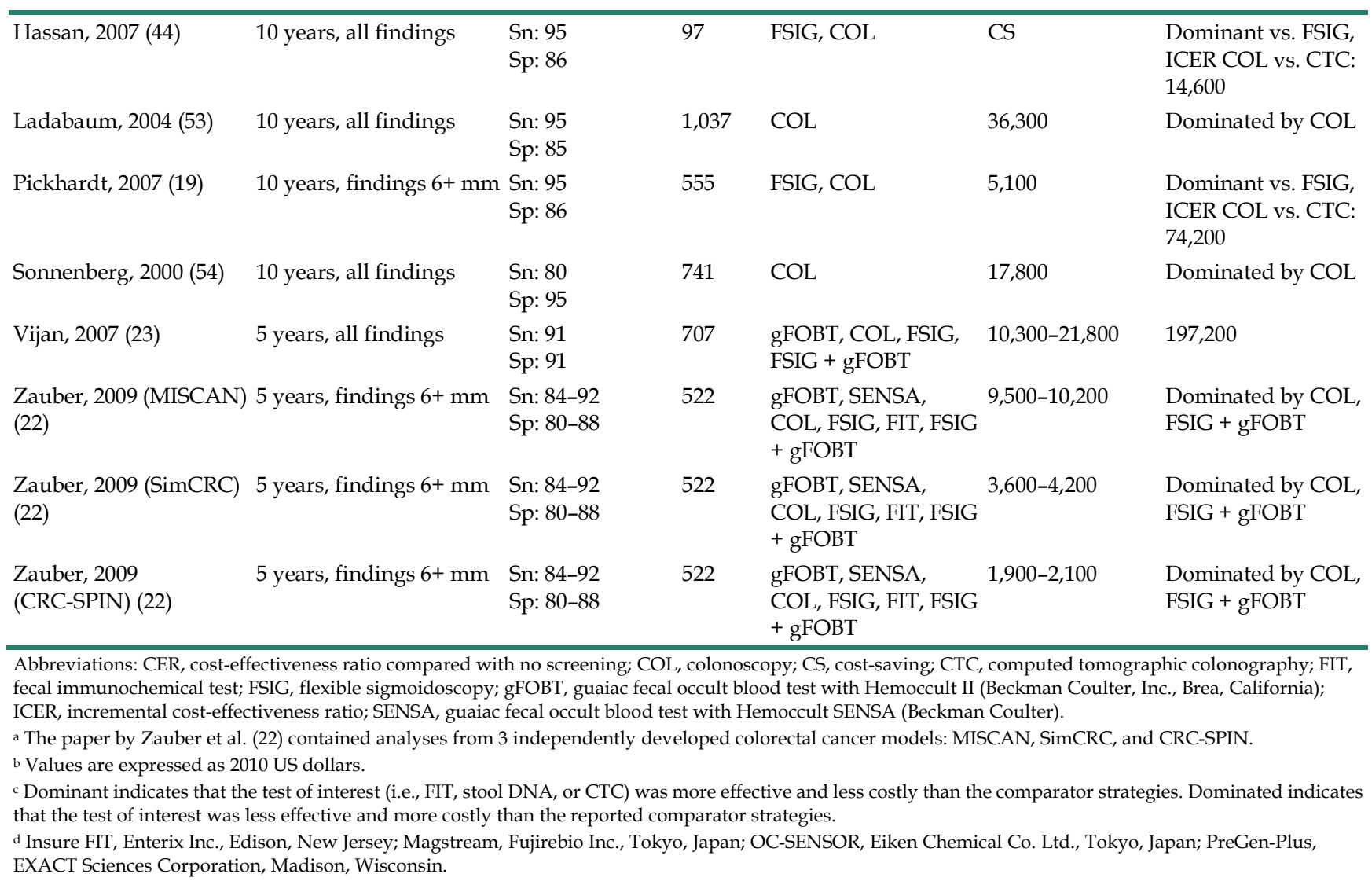

Virtual colonoscopy/CT colonography gained success following trials conducted within the US Army medical system. VC/CT colonography within the US Army started in 2003 through a trial comparing VC/CT colonography and standard optical colonoscopy based out of Walter Reed Army Medical Center, Washington, D.C. Performance characteristics of VC/CT colonography for the detection of colorectal neoplasia in the average risk screening population were assessed. Over 1,200 asymptomatic adults underwent same-day VC/CT colonography and standard optical colonoscopy [25]. The reference standard serving as the comparator for VC/CT colonography and standard optical colonoscopy was the final result(s) on optical colonoscopy. The studied focused on adenomatous polyps 6 or more $\mathrm{mm}$ in size. Any adenoma 10 or more $\mathrm{mm}$ in size or with pathologically confirmed high-grade dysplasia, prominent villous component or focus of invasive malignancy was considered "advanced neoplasia". The study used a polyp-matching algorithm; any polyp was considered to be a true positive match between VC/CT colonography and standard optical colonoscopy if it was of identical diameter $( \pm 50 \%$ margin of error) and appeared within the same colonic segment or within adjacent segments. A patient was considered to have a true positive polyp in one of the three size categories (at least $10 \mathrm{~mm}$ in diameter, at least $8 \mathrm{~mm}$ in diameter, and at least $6 \mathrm{~mm}$ in diameter) when at least one polyp of that size category or larger was identified on both VC/CT colonography and standard optical colonoscopy [25].

Sensitivity (Sn) of VC/CT colonography for adenomatous polyps was $94 \%$ for polyps at least $10 \mathrm{~mm}$ in diameter, $94 \%$ for polyps at least $8 \mathrm{~mm}$ in diameter, and $89 \%$ for polyps at least $6 \mathrm{~mm}$ in diameter [25]. The sensitivity of standard optical colonoscopy for adenomatous polyps was $88 \%, 92 \%$, and $92 \%$ for these three size categories of polyps, respectively [25]. The specificity (Sp) of VC/CT colonography for adenomatous polyps was $96 \%$ for polyps at least $10 \mathrm{~mm}$ in diameter, $92 \%$ for polyps at least $8 \mathrm{~mm}$ in diameter, and $80 \%$ for polyps at least $6 \mathrm{~mm}$ in diameter [25]. Two polyps were malignant and both were detected on VC/CT colonography [25]. One was missed on standard optical colonoscopy before the results on VC/CT colonography were revealed [25]. Pickhardt et al. therefore concluded that VC/CT colonography was a safe and accurate screening method for the detection of colorectal neoplasia in asymptomatic average risk patients, and that VC/CT colonography compared favorably to standard optical colonoscopy [25].

A meta-analysis, however, showed that VC/CT colonography was less sensitive than standard optical colonoscopy for the detection of smaller polyps [26, 
27]. Using a cutoff of $5 \mathrm{~mm}$ polyp size, the exact area under the receiver operating characteristics (ROC) curve (AUC) was significantly higher for standard optical colonoscopy compared to VC/CT colonography $(0.998 \pm 0.006$ vs. $0.884 \pm 0.033, \mathrm{P}<0.005)[23,24]$. Of note, the radiation dose of VC/CT colonography, which was once a concern, may no longer be a barrier [28]. Perisinakis et al. studied the radiation burden and the lifetime attributable risk of radiation-induced cancer in patients who underwent screening VC/CT colonography [28]. It was found that compared with previously published results for 64-slice CT scanners, 256-slice VC/CT colonography was associated with up to $45 \%$ less radiation burden with the cumulative lifetime risk of radiation-induced cancer from screening VC/CT colonography every 5 years between ages 50 to 80 year estimated to be less than $0.2 \%$ times baseline risk [28]. Therefore, the authors believe that VC/CT colonography performed using new low-dose protocols does not justify disapproval of this modality as a CRC screening tool based on radiation exposure-related risk [28].

Recent data regarding flexible sigmoidoscopy has corroborated its benefit. Schoen et al. published in the New England Journal of Medicine that screening with flexible sigmoidoscopy was associated with a significant decrease in CRC incidence and mortality with a number needed to prevent one CRC being 282 (95\% CI, 210 to 427) [29]. Nearly 155,000 patients were randomly assigned to screening with flexible sigmoidoscopy or usual care [29]. The incidence of CRC was 11.9 vs. 15.2 cases per 10,000 person-years in the sigmoidoscopy vs. usual care groups, respectively [29]. Data was calculated with a median follow up of 11.9 years [29]. Overall, this represented a $21 \%$ reduction in the incidence of CRC (relative risk, 0.79; 95\% CI: 0.72-0.85; P<0.001) [29]. In addition, mortality from distal CRC was reduced by $50 \%$ ( 87 vs. 175 deaths, sigmoidoscopy vs. usual care, respectively; $\mathrm{RR}=0.50$; 95\% CI: 0.38-0.64; $\mathrm{P}<0.001$ ) [29]. However, there was no difference seen in reduction of mortality from proximal colorectal cancers (143 vs. 147 deaths, respectively; $\mathrm{RR}, 0.97 ; 95 \% \mathrm{CI}: 0.8$ to $1.2 ; \mathrm{P}=0.81$ ) [29]. The authors did note, however, that the effect on incidence and mortality of proximal CRC with universal colonoscopy still remains unknown. When analyzing the prostate, lung, ovarian, colon cancer trial (PLCO trial) data, Schoen et al. stated that the use of colonoscopy rather than flexible sigmoidoscopy may have increased the number of screening-detected colon cancers by approximately 16 percentage points, raising the numbers from less than $25 \%$ to approximately $40 \%$ with two thirds of this increase being from en- hanced detection of proximal CRC's [29].

The advantages and limitations of current screening methods are summarized in Table 5. Problems with CRC screening modalities currently in use include the lack of adequate diagnostic sensitivity, low overall cost-effectiveness ratio, general invasiveness of the procedures, and poor patient compliance. Even the current gold standard of optical colonoscopy demonstrates significant variability between providers in the detection of adenomas [30]. Therefore, if advancements in population-based CRC screening are not attained in the foreseeable future, then effective Precision Risk Stratification-Based Screening may be a reasonable strategy to achieve overall cost reduction in cancer care with superior outcomes in CRC.

\section{The Potential Future of Colorectal Cancer Screening and Risk Stratification}

Following the guidelines and recommendations for early screening can lead to early detection of CRC for timely potentially curative interventions, which can lead to improved prognosis and reduced CRC mortality at advanced stages. It will be extremely difficult, however, to screen the entire eligible US population (approximately 100,000,000 individuals) mainly due to the technical limitations of the currently recommended screening methods. FOBT or FIT is the easiest and cheapest method of screening, about $\$ 5 /$ per test according to the Current Procedural Terminology (CPT) code; however, FOBT or FIT detects only $30-40 \%$ of CRC and $10 \%$ of adenomas, and thus, is not ideal in prevention of and early interventions for CRC. Optical Colonoscopy (COL) is the current gold standard for detection, takes about one hour and costs about $\$ 250$ to just examine the colon, and several hours and over $\$ 5,000$ (according to the CPT code) if the detected tumor(s) need to be removed endoscopically. Thus, it would require at least 5,000 highly trained professionals, and $\sim 5,000$ colonoscopies working non-stop (24-hours/ day) for 3-years to finish the visual inspection of the colonic mucosa of the entire eligible population of $\sim 100,000,000$ people. Consequently, using COL as a routine screening tool may not only exhaust available resources, but may also have no direct benefit in over $80 \%$ of the eligible population screened, which is expected to be free from colorectal polyps and/or cancer. The utilization of other recommended methods, individually or collectively, is likely to yield less satisfactory outcomes due to either the same limitations of the method, the high associated cost, or the risk of high radiation exposure (Table 5 and Table 6). 
Table 5: Advantages and limitations of current screening methods

\begin{tabular}{|c|c|c|c|}
\hline Methods & Efficiency & Insufficiency or drawbacks & Reference \\
\hline $\begin{array}{l}\text { FOBT or } \\
\text { FIT }\end{array}$ & $\begin{array}{l}\text { Easiest, least expensive method for screening } \\
\text { Reduces cancer mortality } 15 \% \text { to } 33 \% \\
\text { Specificity ranging from } 88 \% \text { to } 98 \%\end{array}$ & $\begin{array}{l}\text { Detects only } 30-40 \% \text { of CRC } \\
\text { Detects } 10 \% \text { of late stage adenomas }\end{array}$ & $18-24$ \\
\hline sDNA & $\begin{array}{l}\text { Sensitivity ranging from } 52 \% \text { to } 91 \% \\
\text { Specificity ranging from } 93 \% \text { to } 97 \%\end{array}$ & Detects only late stage lesions & $25-29$ \\
\hline FSIG & $\begin{array}{l}\text { Directly inspects the mucosal surface } \\
\text { Ability to resect identified abnormalities } \\
\text { Reduces CRC mortality }\end{array}$ & $\begin{array}{l}\text { Fails to detect polyps in the proximal colon, where } \\
40 \% \text { of all cancers occur, Fails to detect } 10-15 \% \\
\text { sigmoid colon cancers }\end{array}$ & $30-40$ \\
\hline COL & $\begin{array}{l}\text { Directly inspects the mucosal surface } \\
\text { Ability to resect identified abnormalities } \\
\text { Reduces CRC mortality } \\
\text { Ability to perform interventions for other diseases } \\
\text { Current gold standard for detection and } \\
\text { treatment }\end{array}$ & $\begin{array}{l}\text { Invasive and time consuming } \\
\text { Requires bowel preparation } \\
\text { Costly } \\
\text { Carries risk of perforation or death } \\
\text { May miss up to } 10-20 \% \text { of polyps }<1 \mathrm{~cm}\end{array}$ & $41-53$ \\
\hline DCBE & $\begin{array}{l}\text { Sensitivity for detecting polyps and cancer are about } 70 \% \\
\text { and } 85 \% \text {, respectively } \\
\text { Less invasive procedure }\end{array}$ & $\begin{array}{l}\text { Doesn't permit removal of identified abnormali- } \\
\text { ties } \\
\text { Less specific screening test }\end{array}$ & $54-56$ \\
\hline CTC & $\begin{array}{l}\text { Sensitivity for detecting adenomas } \geq 5 \mathrm{~mm} \text { ranging from } \\
65-72 \% \\
\text { Sensitivity for detecting larger adenomas ranging from } \\
80-85 \% \\
\text { Less invasive than COL }\end{array}$ & $\begin{array}{l}\text { Delivers a significantly higher amount of radia- } \\
\text { tion exposure }(2-4 \mathrm{rad}) \text { than routine chest radio- } \\
\text { graph }(0.5 \mathrm{rad})\end{array}$ & $57-62$ \\
\hline
\end{tabular}

Table 6: Comparison of the estimated costs of USPSTF recommended screening methods

\begin{tabular}{lllll}
\hline N0 & Screening method & Frequency & Cost/screening $(\$)$ & 10 -year cost $(\$)$ \\
\hline 1 & FOBT or FIT & Annually & $5-10$ & $50-100$ \\
2 & FSIG & Every 5-years & $70-600$ & $140-1,200$ \\
3 & DCBE & Every 5-years & $600-1000$ & $1,200-2,000$ \\
4 & COL & Every 10-years & $250-5000$ & $250-5,000$ \\
\hline
\end{tabular}

Together, these technical limitations and the preparation necessary for the screening examination appear to not only negatively impact the efficiency of CRC screening, but also represent major factors contributing to a low compliance rate amongst the screen-eligible population. As the compliance rate can directly influence the CRC incidence and mortality rate, there is an urgent need to develop more effective and patient-friendly screening methods in an effort to improve screening efficiency, and to increase the patient compliance rate. Based on the following facts: 1. Over $80 \%$ of the eligible population is expected to be free from adenoma or CRC; 2 . Amongst all recommended screening methods, stool cell-based FOBT and FIT are the easiest and most cost-effective tests, and can be carried out on a large scale with an automated detection system; and, 3. None of the recommended screening methods or current approaches can reliably identify the individuals with impending or those at increased risk for metastatic CRC, which accounts for over $90 \%$ of CRC-related death. It is our expectation and consensus that the following strategies may substantially improve the efficiency of and increase the compliance rate of CRC screening.

\section{A. Enhanced accuracy of biomarker-based tests used for CRC screening}

It has been well documented that colorectal carcinogenesis is a multi-stage process, originating from a tiny adenomatous polyp that linearly progresses to adenoma, intra-mucosal adenocarcinoma, onto invasive and metastatic carcinoma - a process that takes 4-10 years. Although the current approach using stool-based testing can detect only $30-40 \%$ of CRC and $10 \%$ of adenomas, the sensitivity and spectrum of this approach can be significantly enhanced with the following methods:

\section{FIT with antibodies to colon cancer associ- ated transcript-I (CCAT-I)}

FIT with antibodies to CCAT-1 is currently undergoing clinical feasibility testing. CCAT-1 is 
up-regulated in the early phases of tumorigensis such as adenomatous polyps and colonic epithelium proximal to tumor [31]. More importantly, CCAT-1 was found to be over-expressed in peripheral blood samples of $40 \%$ of CRC patients as compared to normal healthy controls [31]. This therefore suggests that CCAT-1 expression correlates with extremely small quantity of tumor cells [31]. Extrapolating this into clinical practice, CCAT-1 may be a highly specific and readily detectable marker for CRC either in the blood or stool [31]. Peptide-based antibodies can be easily developed and used for FIT, which could potentially detect CCAT-1 in shed cells of adenomatous polyps in the early stages of carcinogenesis.

\section{Colon mucosal antigens, mAb $3 \mathrm{I}$.I and NPC-I, screening and therapeutic targets (currently in FDA IND Phase I/II trials)}

Similar to CCAT-1, these two antigens are specific to colon cancer cells and are up-regulated in only a small subset of morphologically normal or benign colonic epithelial cells, and subsequently in all their morphologically malignant counterparts making them attractive screening biomarkers [32] [33]. These tumor-membrane protein antigens are extremely immunogenic, and can be targeted with antigen-specific monoclonal antibodies, which spare normal colonic cells while producing effective antibody-dependent colon cancer cell cytotoxicity [32]. A recent study demonstrated proof of therapeutic principle, as tumor membrane protein-based vaccine when administered with an immunoadjuvant can improve oncological outcome following resection of Stage II and III colon cancer [33]. These tumor antigen-specific antibodies are currently being evaluated under FDA-approved Phase-2 trials for the treatment of CRC and pancreatic cancer [32]

Another recent study tested a pre-screening strategy for identifying at-risk patients that should go onto optical colonoscopy based on nano-archtectural changes found as part of field carcinogenesis in the pre-malignant phase of colonic neoplasia [34]. This strategy applied partial wave spectroscopic (PWS) microscopy using an optically quantifiable biomarker $(\mathrm{L}(\mathrm{d}))$ in histologically normal, but nanoscopically altered epithelial cells. The L(d) was found to correlate with colon tumorigenicity in both test and validation cohorts, thereby supporting further testing of this cost-effective minimally-invasive Precision Risk Stratification-Based Screening strategy for colonoscopic pre-screening [34].

Tumor antigen-specific antibodies can be used for the detection of corresponding tumor membrane proteins in shed cells within stool using a generic ul- tra-sensitive quantitative antigen detection system (Immunoliposome polymerase chain reaction, ILPCR), most recently introduced by our collaborators, that provides accurate quantitative measurement of antigens of interest found at low concentrations and across a wide dynamic range [35]. This method is 100-times more sensitive than ELISA, and over 1,500 times more sensitive than current antigen-antibody-based clinical tests. The combination of these new monoclonal antibodies and novel accurate multi-reporter detection methodology stands to significantly increase the sensitivity of detection of adenomatous polyps, and our ability to deliver on a promise of Precision Risk Stratification-Based Screening for colorectal cancer.

\section{Stool cell-based biomarkers for CRC screening (secreted clusterin isoform, intesti- nal alkaline sphingomyelinase, stool DNA, and microRNAs)}

Secreted clusterin isoform (sCLU) has been shown to be released in the blood and stool of patients with colon cancer and has shown potential as a biomarker for population-based CRC screening [36]. At a sCLU quantitative threshold of $88.5 \mathrm{mcg} / \mathrm{ml}$ in blood, sensitivity for differentiating non-neoplastic from neoplastic colorectal neoplasms was $56 \%$ at a specificity of $100 \%$; a cutoff value of $34.6 \mathrm{mcg} / \mathrm{ml}$ sCLU in stool had a diagnostic sensitivity and specificity of $67 \%$ and $84 \%$, respectively [36]. These results serve as the basis for further testing to determine if sCLU can deliver effective and efficient Precision Risk Stratification-Based Screening for colorectal cancer.

Another stool-based biomarker approach to CRC screening involves intestinal alkaline sphingomyelinase, a mucosal enzyme which has been shown to be significantly reduced in neoplasms of the colon and rectum [37]. Alkaline sphingomyelinase activity has been found to be significantly reduced not only in CRC mucosa, independent of cancer stage, but also in microscopically normal appearing peritumoral mucosa [37]. A $\sim 90 \%$ mean reduction of alkaline sphingomyelinase was found in the stool of $C R C$ patients as compared to neoplasm-free controls $(\mathrm{P}<0.0001)$, suggesting yet another practical, cost-effective, biologically relevant method for stool-based biomarker screening.

Next generation-based DNA detection methodology has opened a new frontier in stool DNA screening for colorectal neoplasia. This screening strategy based on advanced multi-marker stool DNA tests has been deemed to be both "biologically rational and user-friendly...for the non-invasive detection 
of both CRC and critical precursor lesions" throughout the colon and rectum [39]. At present, stool based-molecular tests demonstrate sensitivity for CRC of up to $85 \%$, and sensitivity for adenomas $>1 \mathrm{~cm}$ of exceeding $65 \%$ (63\% for $>1 \mathrm{~cm}$, up to $92 \%$ for $>4 \mathrm{~cm}$ adenomas). The specificity of these assays range from 90 to $100 \%$ [39]. Unlike other screening approaches next generation stool DNA testing is unaffected by site within the colon (proximal versus distal), rather adenoma, tumor size impacts rates of detection. Studies are underway to optimize this screening strategy.

Small non-coding RNAs, microRNAs, are also biologically relevant biomarkers. microRNAs have been implicated in many facets of carcinogenesis (apoptosis, cell proliferation, regulation of gene expression). As such these biomarkers are being explored further, not only for screening and early detection of CRC, but also for assessment of prognosis and response to therapy in patients with CRC [38].

\section{Application of normal colonic cell replen- ishment-related unique molecules as a screening tool}

Normal colonic epithelial cells belong to a rapidly self-renewing population of cells replenished by adult gut stem cells, located at the base of the colonic crypts. These cells constantly proliferate, differentiate, and move upwards (towards the apex) to replace aged or damaged apical cells facing the colonic lumen [40-43]. During the normal replenishment process, the apical cells are shed into the colonic lumen as a result of programmed cell death with significant apoptotic, necrotic, telomere, and telomerase-related alterations. In contrast, adenomatous polyps or CRC may originate from aberrant proliferation of tumor stem cells. Thus, cell shedding from normal and tumoral mucosa is likely to result from different mechanisms. More importantly, shed cells from normal replenishment and those shed from tumors are likely to differ substantially in structural, molecular, and biochemical profiles. Therefore, the unique molecular and biochemical profiles of normal colonic cell replenishment can be potentially used as a screening tool to differentiate between shed cells from normal replenishment and from those derived from tumors themselves. This application of normal colonic cell replenishment-related screening approach would have the following advantages: 1 . ease of collection and analysis of a large number of samples; 2 . low cost of analyses; 3. the baseline of normal replenishment-related changes can be established before age 40 , which can be used to monitor age-related changes relevant to colorectal carcinogenesis; 4 . unique molecules related to the normal replenishment process can be used as "absorbers" to remove unwanted molecules in testing samples for enrichment of low levels of carcinogenesis-related molecules either due to low copy number of mRNAs or due to a limited number of tumor cells; and, 5 . it can effectively differentiate between normal and tumor shed cells.

\section{Integration of biomarker-based screening strategies (CCAT-I; colon mucosal antigens, mAb 3I.I and NPC-I; stool testing for se- creted clusterin isoform, intestinal alkaline sphingomyelinase, stool DNA, and mi- croRNAs; normal colonic cell replenish- ment-related unique molecules) to advance Precision Risk Stratification-Based Screening}

Together, successful development and implantation of the aforementioned four screening strategies may significantly increase the sensitivity of CRC detection; what's more it would enable Precision Risk Stratification-Based Screening for CRC. As these assays are substantially easier to use and cheaper than screening FSIG, DCBE, COL, CTC, they can be used individually or collectively as the first line screening tool(s) to test all age-appropriate, asymptomatic individuals annually in a well-tolerated, biologically relevant, accurate and cost-efficient manner during routine population-based annual health promotion and disease prevention examinations. If a given individual is identified as high-risk for CRC based on aberrant alterations in two to three consecutive tests, then referral for standard optical colonoscopic screening would be indicated. This approach would not only increase screening compliance, but would also amount to overall health care system cost savings (Table 6). In addition to the above novel approaches supporting Precision Risk Stratification-Based Screening for CRC, there are a number of well-established and tested methods, which can be used individually or collectively applied as a panel for stool or blood based tumor cell detection.

\section{i. DNA Methylation}

A variety of hyper-methylated genes in stool samples have been reported as biomarkers for the detection of adenomas or colorectal carcinomas [44-46]. A recent meta-analysis of nineteen studies including 2,356 patients concluded that, "hyper-methylated gene panels are not currently accurate enough to be used alone for colorectal neoplasia screening. The discovery and evaluation of additional biomarkers with improved sensitivity and specificity is necessary" [47]. Please refer to the manuscript in this special edition by Summers et al., Serum-based 
DNA methylation biomarkers in colorectal cancer: Potential for screening and early detection.

\section{ii. Blood and stool-based detection of known gene mutations}

While the adenomatous polyposis coli (APC) gene mutation is a key molecular step in adenoma formation, progression from adenomas to invasive carcinoma is a complex multi-step process, involving mutations of the deleted in colorectal carcinomas (DCC), k-ras, and p53 genes [48-51]. Recent reports have suggested that autoantibodies can be detected prior to clinical diagnosis of invasive cancer [52]. Informative p53 peptides were found by using an auto-antibody microarray with 15-mer overlapping peptides covering the complete p53 sequence [52]. These selected peptides were then evaluated in a blinded case-controlled study of serum samples obtained from women who developed CRC following recruitment into the United Kingdom Collaborative Trial of Ovarian Cancer Screening in which enrolled study patients gave multiple blood samples. Using a process of matching CRC patients to age-matched female controls with no history of cancer it was found that four p53 peptides identified $26 \%$ of CRC cases (specificity 95\%) with a median lead time of 1.4 years (range: 0.12 to 3.8 years) before the clinical diagnosis of CRC was made [52]. Although early in its development, this clinical trial alludes to a potential auto-antibody signature that is present and detectable prior to the clinical presentation of malignant disease. p53 auto-antibodies may therefore have relevance and value in CRC screening. Recently, a number of new mutations, including DNA polymerase $\beta(\operatorname{pol} \beta)$ and histone deacetylase SIRT1, have been found to promote colorectal carcinogenesis and progression [53, 54]. Blood-based or stool-based testing for detection of these mutations has been reported to be more sensitive than FOBT and FIT in CRC detection [55].

\section{iii. Circulating cancer cells (CTCs)}

Recently, great efforts have been made to detect CTCs in peripheral venous blood. With a highly automated immunomagnetic CTC assay system, 50-70\% of patients with metastatic cancers are found to have elevated CTC levels [56]. However, CTCs are not detected in $30-50 \%$ of peripheral blood samples of patients with metastatic cancer, but are seen in more than $30 \%$ of breast, colon, and other cancer patients without clinical or histopathological signs of systemic spread of disease [56-58]. Unfortunately, no method currently exists that can reliably detect and define circulating metastatic-initiating cells in the earliest stages of neoplasia in which the disease could be cured or prevented from progression to invasive malignancy [56-58]. We therefore advocate for further investigative research into circulating tumor cells and metastatic initiating cells (potentially of cancer stem cell origin) as a potential avenue of approach pursuant to Precision Risk Stratification-Based Screening for CRC.

\section{iv. Other screening methods}

A number of well-established and validated methods, including stool-based mutation and microsatellite instability (MSI) tests, serum markers, various biomarkers, and stem cell-related markers, could also be used individually or collectively as a screening tool. These are covered in an accompanying manuscript; please refer to the manuscript in this special edition by Langan et al. Molecular Staging using Cancer Stem Cell Markers: A Paradigm Shift in the Care of Colorectal Cancer.

\section{B. An Effort to Enhance the Gold Stand- ard (Colonoscopy)}

Although colonoscopy has been recognized as the 'gold standard,' as it can detect and also remove detected mucosal abnormalities, it is not a desirable screening tool for the following reasons: 1 . it is invasive and associated with a risk of colonic perforation $(0.3 \%)$ and death (one of about 5,000 cases) [59-62]; 2 . it is time-consuming, requires bowel preparation and sedation prior to the procedure, taking a total of 3-5 hours to complete the entire procedure, amounting to productive work loss and negative quality of life impact on the patient; 3 . it costs about $\$ 250$ to examine the colonic mucosa, and over $\$ 5,000$ if the detected mucosal tumors are to be removed; 4 . it may fail to inspect the entire colon mucosa in $10-15 \%$ of cases and overlook up to $10-20 \%$ of polyps $<1 \mathrm{~cm}[24$, 63-68]; and, 5 . it has direct benefit in only about $20 \%$ of the eligible screening population, as a vast majority of the population are expected to be free from colonic tumors or pre-malignant mucosal abnormalities (Table 5).

Supplemental methods have been utilized to enhance visualization of mucosal abnormalities during fiber-optic endoscopy, such as the use of dyes instilled into the gastrointestinal tract at time of screening examination (chromoendoscopy using dyes, or virtual chromoendoscopy using narrow band imaging with blue and green filters). For example, methylene blue has been in use to facilitate identification of colonic mucosal dysplasia in patients with ulcerative colitis. A variety of other methodologies have been employed to improve identification of mucosal abnormalities without the use of dyes, including 
magnification endoscopy, confocal microscopy, optical coherence tomography, and narrow-band imaging. This latter technique (NBI) uses ambient light in the range of blue and green wavelengths to improve mucosal and vascular structure delineation during optical colonoscopy. Please refer to the manuscript in this special edition by Backman and Roy, Advances in Biophotonics Detection of Field Carcinogenesis for Colon Cancer Risk Stratification.

During the past 20-years, great efforts have been made to develop alternative modalities to improve the screening function of standard optical colonoscopy. Among a variety of newly developed devices, virtual colonoscopy (VC) or computed tomographic (CT) colonography, which utilizes computer virtual-reality techniques to construct a 3-D patient-specific model based on the CT images of the colon mucosa to identify polyps or CRC, has gradually gained in popularity (as discussed above; please refer to the manuscript in this special edition by Young and Womeldorph, Colonoscopy for Colorectal Cancer Screening: An effective but imperfect method). Results from three independent clinical trials have shown that both VC/CT colonography and standard optical colonoscopy have a comparable performance for detecting polyps of $\geq 10$ $\mathrm{mm}$ in size $[25,69,70]$, indicating that $\mathrm{VC}$ can be a potentially useful tool to supplement standard optical colonoscopy for CRC screening. However, the VC/CT colonography system has a significant drawback: it delivers 2-4 rads of radiation exposure to the patient's abdomen, compared to 0.5 rads of radiation exposure delivered by a routine chest radiograph (Table 5) [71]. Although Perisinakis found radiation-induced cancers to be low (discussed above), we still do not know the long-term effects of these repeated doses of radiation if VC/CT colonography was adopted as a routine screening tool for the entire eligible population [71].

Despite the great efforts made to reduce the cumulative radiation exposure [72, 73], the current VC/CT colonography system still has to deliver a high dosage of radiation in order to achieve satisfactory images [72, 73]. Although low-radiation dose CT and high resolution magnetic resonance colonography could operate under a substantially reduced radiation dosage, they are more sensitive to motion and other artifacts, and have a substantially lower spatial resolution; thus, they are facing some challenges to detect small or flat polyps, compared to VC/CT colonography [74]. In addition, they are more costly with economic burden to both the patient and the society. Because of these drawbacks associated with VC/CT colonography and their modified derivatives, it is our consensus that further studies are needed to establish sufficient evidence basis to allow recom- mending this modality as a universal screening tool for the entire eligible population.

Importantly, when one considers the possible adverse effects of standard optical colonoscopy we are moved to continue the search for alternative population-based screening approaches. The data above suggest that if we were to screen the entire eligible population with standard optical colonoscopy that would amount to 300,000 colonic perforations and 20,000 procedure-related deaths. When considering these possible adverse outcomes, the risk of serial radiation exposure from $\mathrm{VC} / \mathrm{CT}$ colonography seems comparatively less harmful, particularly when procedural deaths from VC/CT colonography will be near, or at zero.

\section{The Need to Enhance CRC Risk Pre- diction}

Cancer risk prediction models have been widely used to identify individuals at high risk of developing cancer, who can then be offered individually-tailored clinical management, targeted screening and interventions to reduce the burden of disease. There are multiple modalities and theories pertaining to risk stratification for CRC. In this patient-centered, quality-driven, and value-based purchasing era in oncology, we need to identify those patients who would most benefit from the various screening modalities. Cancer risk predication models are also useful for research purposes to identify new risk factors. A number of risk factors, including family history of CRC, history of CRC in first-degree relatives, familial adenomatous polyposis, Lynch syndrome, MYH-associated polyposis, hereditary mixed polyposis, hyperplastic polyposis, cigarette smoking, body mass index (BMI), and others, have been reported to promote colorectal carcinogenesis and tumor progression [94-96]. A number of CRC risk prediction models, including those of the American Society of Anesthesiologists (ASA) and the Physiological and Operative Severity Score for the enumeration of Mortality and Morbidity (POSSUM), Risk Index Working Group scoring system, separate CRC absolute risk, and biomarker-based prediction [75-79], have been introduced. However, "none of the markers studied have been proven to be of significant, independent value, justifying implementation in daily clinical practice" [80], and "there is no model that sufficiently covers the known risk factors for colorectal cancer that is suitable for assessment of people from across the full range of risk" [81]. One example of the limitations of the current risk prediction models is that it has been well documented that up to $25 \%$ of early stage (Stage I or II), node-negative CRC patients 
develop systemic metastasis or recurrent lesions, while none of the current approaches can reliably identify this at-risk subset of patients for early interventions. Risk factors such as age, family history, known genetic predisposition, geographic origins and race can be incorporated into screening for the purpose of Precision Risk Stratification-Based Screening for colorectal cancer.

\section{Risk Screening Index}

Using a simplified risk index to identify patients at low risk for developing CRC, Lin et al. described a unique stratified screening modality. The patient population consisted of asymptomatic patients who had previously undergone standard optical colonoscopy and were randomized retrospectively to two subgroups, derivation and validation [21]. A risk index based on age, sex and CRC family history was created from the derivation group. Data from three screening strategies were analyzed in the derivation group, and then validated [(1) universal optical colonoscopy, (2) universal VC/CT colonography, (3) stratified strategy of optical colonoscopy for high risk patients and VC/CT colonography for low risk patients] [21]. The authors assumed screening optical colonoscopy to have $96 \%, 87 \%$ and $77 \%$ sensitivity for detecting polyps $\geq 10 \mathrm{~mm}, 6-9 \mathrm{~mm}$ and $<6 \mathrm{~mm}$ in size, respectively [21]. Initial findings in the derivation group showed detection of advanced neoplasia in $94 \%$ of patients with universal optical colonoscopy, and in 70\% with universal VC/CT colonography [21]. This strategy had the largest total number of procedures performed, and the largest number of patients undergoing both procedures [21]. Using the stratified strategy via the risk index, $92 \%$ of those with advanced neoplasia were detected; $68 \%$ required optical colonoscopy and 36\% VC/CT colonography [21]. Only $4 \%$ of patients underwent both procedures [21]. Validation in the second group was then undertaken and findings were consistent with those of the derivation group.

In summary, this risk stratification strategy detected approximately as many neoplasias as universal optical colonoscopy, reduced the number of optical colonoscopies performed by one third, and only $4 \%$ of patients required both procedures [21]. In addition, the cost of this risk stratification strategy was less per advanced neoplasia detected than if universal optical colonoscopy was applied to the screen-eligible population. The clinically useful, practical aspect of this study is that through the use of simplistic risk stratification, patients can be assigned into more appropriate Precision Risk Stratification-Based Screening groups [21]. Low risk individuals receive less invasive, less expensive techniques, and those at high risk receive standard optical colonoscopy [21]. Current data suggest optical colonoscopy volume to be upwards of 7 million per year [21]. However, there are 42 million Americans over the age of 50 that have not undergone CRC screening [21]. Lin et al. therefore conclude that it is unlikely that our medical community and healthcare systems can meet the needs of universal optical colonoscopy [21]. Precision risk stratification and the use of a stratified screening system as described may not only increase CRC screening compliance but also be cost effective for the entire screen eligible population. The clinical value of this simplified risk index as a routine screening tool for the eligible population, however, remains to be seen for the following reasons: 1 . the sample size (a total of 3,005 asymptomatic persons aged 50 years or older) was too small to draw any conclusive statement applicable to the general population; 2 . after its publication in 2006, the reported results have not been independently validated, and the article has been cited only by four PubMed Central articles (two of the four by the author himself); and, 3. none of the major national organizations or professional societies has recommended this risk index system for population-based CRC screening. Issues insufficiently addressed by the current risk stratification systems are shown in Table 7. Further, Barriers and obstacles to compliance with recommended screening are shown in Table 8.

Table 7: Issues insufficiently addressed by the current risk stratification systems

\begin{tabular}{ll}
\hline$\#$ & Issues and facts \\
\hline 1 & Racial disparity \\
1. There is about a $20 \%$ greater incidence of, and approximately a $40 \%$ greater death rate from, colorectal cancer in African \\
American, compared to Caucasian, patients. \\
2. There are racial differences in stage-specific outcomes. \\
Predisposition of genetic defects \\
A. A family history of colorectal carcinoma, $15-20 \%$ \\
B. Hereditary non-polyposis colon cancer (HNPC) accounts for $4 \%-7 \%$ \\
C. Familial adenomatous polyposis (FAP), for about $1 \%$.
\end{tabular}


D. Chronic ulcerative colitis, Crohn's colitis, familial juvenile polyposis, and others, $1 \%$

E. The risk in a 40-year-old person with a family history of colorectal carcinoma is comparable to that in an average-risk 50-year-old person.

3

Tumor biology

A. Tumor size, shape, and location

B. About $25 \%$ node-negative stage I and II cases develop metastasis, while $50 \%$ node positive cases remains recurrence-free

4. High CRC incidence areas (epidemiological clusters)

$5 \quad$ Military and civilian

$5 \quad$ Strategies and systems for implantation of screening

$6 \quad$ Post-polypectomy surveillance

7

Cost effectiveness

Table 8: Barriers and obstacles to compliance with recommended screening

\begin{tabular}{|c|c|}
\hline \# & Barriers and obstacles \\
\hline 1 & $\begin{array}{l}\text { Physician-related } \\
\text { A. Inconsistent and frequently changing guidelines and recommendations among societies } \\
\text { B. Failure to avoid common errors } \\
\text { C. Patients are screened for colorectal cancer (CRC) with only a digital rectal exam. } \\
\text { D. Patients are screened for CRC in the office with a single sample from a stool blood test. } \\
\text { E. Patients with a history of adenomatous polyps in a first-degree relative are not } \\
\text { Identified as people at increased risk. } \\
\text { F. Providers have cultural assumptions that inhibit frank discussion, which could lead to a } \\
\text { clear recommendation for screening. } \\
\text { G. Patients with a positive FOBT, FIT, stool DNA, CT colonography, double-contrast } \\
\text { barium enema, or flexible sigmoidoscopy never receive an order for a complete } \\
\text { diagnostic exam. } \\
\text { H. There is no follow up on patients referred for a complete diagnostic exam. } \\
\text { I. Practitioners recommend screening with colonoscopy for those at average risk more } \\
\text { often than every } 10 \text { years or CT colonography, double-contrast barium enema, or } \\
\text { flexible sigmoidoscopy more often than every five years. } \\
\text { J. Screening is started earlier than age } 50 \text { for average-risk } \\
\text { K. Non adherence to ACS recommendation regarding essential elements for improved } \\
\text { screening. } \\
\text { L. Confusion about priorities and goals } \\
\text { M. Lack of confidence in the efficacy and acceptability of screening tests }\end{array}$ \\
\hline 2 & $\begin{array}{l}\text { Patient-related } \\
\text { A. Incorrectly low analysis of personal risk } \\
\text { B. Fear of finding cancer }\end{array}$ \\
\hline 3 & $\begin{array}{l}\text { System- or test-related } \\
\text { A. Inconvenience/invasiveness of some tests } \\
\text { B. Insurance/reimbursement related issues } \\
\text { C. Inadequate resources }\end{array}$ \\
\hline
\end{tabular}

\section{Risk Stratification by and within Race}

Although race has been accepted as a CRC risk factor by the American College of Gastroenterology it has yet to become the basis of a modified consensus recommendation for screening. Data suggests that blacks have a higher incidence of, at a younger age (45 years), and higher mortality from CRC [82]. Socioeconomic status has a significant influence in CRC screening (e.g. access, education, outreach, compliance) within racial groups. Lieberman et al. investigated racial disparities in CRC colonoscopic screening by assessing prevalence rates and location of large polyps in asymptomatic black vs. white patients [83]. Results of compounded colonoscopic data analyzed in a multivariate fashion adjusting for age, sex and family history of CRC was published in JAMA in 2008 [83]. Compared to whites, blacks did in fact have a higher prevalence of large polyps (>9 $\mathrm{mm}: 7.7 \% \mathrm{vs}$. $6.2 \% ; \mathrm{P}<.001$ ) [83]. In addition, a sub-set analysis found that blacks over the age of 60 had statistically more large $(>9 \mathrm{~mm}$ ) proximal polyps as compared to whites (men, $p=0.03$; women, $p$ <0.001) [83]. If these results are validated, the use of sigmoidoscopy in the older black population should be addressed since it may be less effective in a population, which has increased proximal neoplasia. This trial exemplifies the need for individualized Precision Risk Stratification-Based Screening for CRC. Gone are the days of blanket guidelines for all individuals in the screen 
eligible population at large. Issues insufficiently addressed by the current risk stratification systems are summarized in Table 7. These include racial disparities, predisposition to CRC of genetic defects, impact of tumor biology, high CRC incidence geographic regions, military versus civilian population-based disparities, strategies and systems for screening, post-polypectomy surveillance and cost-effectiveness issues.

\section{Risk stratification - microRNAs, proteins and stem cells in early CRC}

It has been well documented that expression levels of both microRNAs and proteins of the basement membrane subunits change substantially during colorectal carcinogenesis, and are significantly down-regulated during CRC invasion [84-86]. It has also been reported that the expression of the collagen IV or collagen I mRNAs or proteins can directly and significantly impact the lineage differentiation of both adult and embryonic stem cells [87, 88]. Finally, it been suggested that tumor stem cells are the primary seeds for both invasive and metastatic colorectal cancer [103-105]. Please refer to the manuscript in this special edition by Langan et al. Molecular Staging using Cancer Stem Cell Markers: A Paradigm Shift in the Care of Colorectal Cancer, as well as the manuscript by Mazeh et al. The Diagnostic and Prognostic Role of microRNA in Colorectal Cancer - A comprehensive review.

\section{To Enhance the Tailoring of Therapy in Patients with CRC}

Up to $25 \%$ of early stage (AJCC Stage I or II), node-negative CRC patients develop systemic metastasis or recurrent disease, and none of the current approaches can reliably identify patients for early potentially curative interventions. Diligent efforts are underway to improve staging and provide individualized risk assessment for early multi-modality therapy. One recommended approach involves testing all lymph nodes (LN) after resection of CRC for GUCY2C by RT-PCR (please refer to the manuscript in this special edition by Terry Hyslop and Scott A. Waldman, Molecular staging of node negative patients with colorectal cancer). GUCY2C, a signaling protein synthesizing cyclic GMP, is selectively expressed by intestinal cells [89-98], and over-expressed by all primary and metastatic colorectal cancer cells [90, 91, 99-105]. The prognostic utility of detecting occult tumor cells in lymph nodes by GUCY2C RT-PCR was explored in a prospective multi-center blinded clinical trial [106]. Enrollment of 257 patients with pN0 colorectal cancer provided 2,570 nodes for histology and GUCY2C RT-PCR. Patients were followed for a me- dian of 24 months (range: 2-63 months) and main study outcomes were time to recurrence of CRC, and disease-free survival. Multivariate analyses revealed that GUCY2C in lymph nodes was an independent marker of prognosis and patients who harbored occult CRC metastases exhibited earlier time to recurrence and reduced disease-free survival [106]. Moreover, the emergence of quantitative RT-PCR provides a unique opportunity to estimate occult tumor burden across the regional lymph node network to precisely estimate prognostic risk in CRC. Indeed, occult tumor burden was an independent marker of prognosis, with near perfect identification of node-negative CRC patients who progress to metastatic recurrence [107-110]. This type of approach is likely to enhance individualized therapy by identification of individuals with impending, or increased risk of, metastatic CRC for early interventions. In that context, adherence to quality surgical and staging efforts, enabling frontline physicians with individualized clinical decision support systems, as well as eliminating barriers and obstacles preventing compliance with recommended screening is imperative (Table 5).

\section{E. Widespread dissemination of CRC cancer screening guidelines}

Although it has been shown that risk stratification and screening modalities can decrease the incidence of CRC, physician knowledge of the data is a crucial factor to improving risk identification, screening, early detection, treatment and outcomes in CRC (Table 8). The result of a recently conducted trial testing the knowledge of internists, family practitioners and gastroenterologists on the screening initiation point in CRC was alarming [111]. The trial utilized an anonymous web-based survey which was sent to $10 \%$ of American Medical Association members [111]. Results of 512 responders found a dismal average knowledge score of $37 \pm 18 \%$ [111]. Of note, gastroenterologists averaged higher scores compared to internists, correctly identifying the screening initiation point for African-Americans and patients with a family history of CRC, respectively [111]. In a separate study, knowledge deficiency was also found within internal medicine residents from two academic training facilities. A survey assessing knowledge of screening recommendations for patients with a family history of CRC, FAP and HNPCC was conducted [112]. Over $80 \%$ of residents completed the survey, and it was found that responders lacked the appropriate risk assessment skills and knowledge to accurately implement current guidelines [112]. Although small study populations, these trials allude to a lack of knowledge amongst practicing physicians and those 
in training for screening guidelines in high-risk CRC populations. These studies address a major barrier to improving Precision Risk Stratification-Based Screening and survival in CRC. If health practitioners are unaware of current CRC screening guidelines, we as a medical community will not be able to move forward with reducing the incidence or mortality of CRC. We believe that much needs to be done to improve educational awareness of evidence-based screening guidelines and risk assessment skills (Table $8)$.

It was also found that $70 \%$ of physicians practicing $>5$ years stated a lack of insurance reimbursement for early referral for standard optical colonoscopy as a barrier to CRC screening guidelines [111]. In response to this finding we would like to address recently published results from Ramsey et al. assessing whether health insurance coverage of CRC screening varied based on risk stratification [113]. Data was obtained through a web-based and mail-based survey of health insurance plans and medical directors [113]. Questions pertained to their health organization's policies regarding coverage for CRC screening for patients at average and high risk, and also whether the insurer had a concrete definition of increased risk for CRC [113]. From the 133 responders (11\%), results found that all plans covered screening for average and high risk individuals [113]. Seventy-five percent of responders stated their organization had a definition for high risk for CRC [113]. Coverage was included for earlier onset of screening and more frequent intervals for high risk patients [113]. However, respondents did state that coverage was determined by "physician discretion" [113]. In summary, this survey found that most insurers did in fact offer enhanced coverage for high risk CRC screening; however, it was at the discretion of the physician [113]. Therefore, we strongly believe that physicians as a whole need be made aware of Precision Risk Stratification-Based Screening approaches to CRC and current evidence-based CRC screening guidelines.

\section{Conclusion}

Improvements in CRC survival have been observed over recent decades; however, they have been modest. As an oncologic community we must strive for superior outcomes in this deadly disease. In 2012, 143,460 new cases and 51,690 deaths were estimated [114]. This disease-associated mortality is unacceptable. The US civilian population has been found to have screening compliance rates of only $5 \%$ to $60 \%$ amongst insured patients, and even lower rates in uninsured and minority patient populations [8]. We believe much can be learned from the US military
CRC screening program, and these techniques should cross over into civilian health care. In addition, the sensitivity of biochemical screening tests should be enhanced through next generation methods measuring novel biomarkers. In addition to the aforementioned novel approaches, there are a number of well-established and tested methods, which can be used individually or collectively as a panel for stool-based or blood-based tumor cell detection. These include, DNA methylation, blood- and stool-based detection of known mutations such as p53, pol B, and SIRT1, since blood- or stool-based mutational testing for the detection of these mutations in CRC has been reported to be more sensitive than FOBT and FIT in CRC detection. In addition, we advocate for further investigative research into circulating tumor cells and metastatic initiating cells (potentially of cancer stem cell origin).

Along with these novel biochemical screening modalities we believe universal colonoscopy should be used as a routine screening tool only in the following individuals: those with aberrant alterations in 2-3-consequent stool cell-based tests, a family history of CRC, HNPCC, FAP, chronic ulcerative colitis, Crohns colitis, familial juvenile polyposis, a predisposition related to other cancer susceptibility genes, African-Americans and those in high-CRC incidence areas, and known polyp formers. Other individuals should be risk stratified and a stratified screening system implemented based on risk prediction - Precision Risk Stratification-Based Screening (PRSBS) for Colorectal Cancer. Along with this, we believe there is a general lack of adequate physician knowledge in CRC screening, and that it is imperative to take decisive steps to improve educational awareness of evidence-based screening guidelines and risk assessment skills and processes.

\section{Abbreviations}

ACG: American College of Gastroenterology

ACR: American College of Radiology

ACS: American Cancer Society

ACS-MSTF: American Cancer Society (ACS) US Multi-Society Task Force (MSTF)

AJCC: American Joint Committee on Cancer

AUC: area under the curve

BBN: Bayesian Belief Network

CCAT-1: Colon cancer associated transcript-1

(CCAT-1)

CDSS: Clinical decision support systems

COL: Standard Optical Colonoscopy

CPG: Clinical practice guideline

CRC: colorectal cancer

CT: computed tomography 
CTC: computed tomographic colonography

DCBE: double-contrast barium enema

FIT: fecal immunochemical tests

FOBT: fecal occult blood testing

GUCY2C: guanylyl cyclase C

H\&E: hematoxylin and eosin

IHC: immunohistochemisty

MHS: Military Health System

mlBBN: Machine learned Bayesian Belief Network

PRSBS: Precision risk stratification based screening

RDA: Representational difference analysis

ROC: receiver operating characteristics curve

RT-PCR: reverse transcriptase polymerase chain reaction

sDNA: stool DNA test

Sn: sensitivity

Sp: specificity

TNM: Tumor-Node-Metastasis

U.S.: United States

USMCI: United States Military Cancer Institute

USPSTF: United States Preventive Services Task

Force

VC: virtual colonoscopy (also CT colonography)

\section{Acknowledgement}

The authors are grateful to Tiffany Felix for her editorial assistance with this collaborative effort.

Funding: This work is supported by the Telemedicine and Advanced Technology Research Center, the Henry M. Jackson Foundation for the Advancement of Military Medicine, the California Oncology Research Institute, INCORE, International Consortium of Research Excellence of the Theodor-Billroth-Academy [TBA ${ }^{\circledR}$ ], and the United States Military Cancer Institute.

Contributing Author Declaration: We certify that all individuals who qualify as authors have been listed; each author has participated in one or more of the following areas: conception and design of this work, the acquisition and/or analysis of data, the writing, and/or critical revision of the document, and supervision of this cooperative research effort. All contributing authors approve of the submission of this version of the manuscript and assert that the document represents valid work. If information derived from another source was used in this manuscript, we obtained all necessary approvals to use it and made appropriate acknowledgements in the document. All contributing authors take public responsibility for this work.

Disclaimer: The views expressed in this manuscript are those of the authors and do not reflect the official policy of the Department of the Army, the Department of the Navy, the Food and Drug Administration, the Department of Defense or the United States Government.

Copyright protection: Some of the contributing authors are military service members (or employees of the U.S. Government: TAS, SRS, PY, CW, AS), and this work was prepared as part of their official duties. Title 17 U.S.C. 105 provides the "Copyright protection under this title is not available for any work of the United States Government." Title 17 U.S.C. 101 defines a U.S. Government work as a work prepared by a military service member or employee of the U.S. Government as part of that person's official duties.

\section{Competing Interests}

The authors have declared that no competing interest exists.

\section{References}

1. Siegel R, Ward E, Brawley O, Jemal A. Cancer statistics, 2011: the impact of eliminating socioeconomic and racial disparities on premature cancer deaths. CA Cancer J Clin 2011; 61: 212-236.

2. Bilchik AJ, DiNome M, Saha S et al. Prospective multicenter trial of staging adequacy in colon cancer: preliminary results. Arch Surg 2006; 141: 527-533.

3. Manfredi S, Bouvier AM, Lepage $\mathrm{C}$ et al. Incidence and patterns of recurrence after resection for cure of colonic cancer in a well defined population. Br J Surg 2006; 93: 1115-1122.

4. Singh $\mathrm{H}$, Turner $\mathrm{D}$, Xue L et al. Risk of developing colorectal cancer following a negative colonoscopy examination: evidence for a 10 -year interval between colonoscopies. JAMA 2006; 295: 2366-2373.

5. Pilati P, Mocellin S, Bertazza L et al. Prognostic value of putative circulating cancer stem cells in patients undergoing hepatic resection for colorectal liver metastasis. Ann Surg Oncol 2012; 19: 402-408.

6. Long JR, Frew MI, Brazaitis MP. Virtual colonoscopy in the US Army: current utilization at the Walter Reed Army Medical Center. Abdom Imaging 2011; 36: 149-152.

7. Brounts LR, Lehmann RK, Lesperance KE et al. Improved rates of colorectal cancer screening in an equal access population. Am J Surg 2009; 197: 609-612.

8. Zhu K, Devesa SS, Wu H et al. Cancer incidence in the U.S. military population: comparison with rates from the SEER program. Cancer Epidemiol Biomarkers Prev 2009; 18: 1740-1745.

9. Stojadinovic A, Bilchik A, Smith D et al. Clinical Decision Support and Individualized Prediction of Survival in Colon Cancer: Bayesian Belief Network Model. Ann Surg Oncol 2013 Jan;20(1):161-74.

10. Fan J, Peng Z, Zhou C et al. Gene-expression profiling in Chinese patients with colon cancer by coupling experimental and bioinformatic genomewide gene-expression analyses: identification and validation of IFITM3 as a biomarker of early colon carcinogenesis. Cancer 2008; 113: 266-275.

11. Force USPST. Screening for colorectal cancer: U.S. Preventive Services Task Force recommendation statement. Ann Intern Med 2008; 149: 627-637.

12. Levin B, Lieberman DA, McFarland B et al. Screening and surveillance for the early detection of colorectal cancer and adenomatous polyps, 2008: a joint guideline from the American Cancer Society, the US Multi-Society Task Force on Colorectal Cancer, and the American College of Radiology. Gastroenterology 2008; 134: 1570-1595.

13. Rex DK, Johnson DA, Anderson JC et al. American College of Gastroenterology guidelines for colorectal cancer screening 2009 [corrected]. Am J Gastroenterol 2009; 104: 739-750.

14. Siegel RL, Ward EM, Jemal A. Trends in colorectal cancer incidence rates in the United States by tumor location and stage, 1992-2008. Cancer Epidemiol Biomarkers Prev 2012; 21: 411-416.

15. Fearon ER, Vogelstein B. A genetic model for colorectal tumorigenesis. Cell 1990; 61: 759-767. 
16. Zauber AG, Winawer SJ, O'Brien MJ et al. Colonoscopic polypectomy and long-term prevention of colorectal-cancer deaths. N Engl J Med 2012; 366: 687-696.

17. Sacher-Huvelin S, Coron E, Gaudric M et al. Colon capsule endoscopy vs. colonoscopy in patients at average or increased risk of colorectal cancer. Aliment Pharmacol Ther 2010; 32: 1145-1153.

18. Sidransky D, Tokino T, Hamilton SR et al. Identification of ras oncogene mutations in the stool of patients with curable colorectal tumors. Science 1992; 256: 102-105.

19. Dong SM, Traverso G, Johnson C et al. Detecting colorectal cancer in stool with the use of multiple genetic targets. J Natl Cancer Inst 2001; 93 : 858-865.

20. Imperiale TF, Ransohoff DF, Itzkowitz SH et al. Fecal DNA versus fecal occult blood for colorectal-cancer screening in an average-risk population. N Engl J Med 2004; 351: 2704-2714.

21. Lin OS, Kozarek RA, Schembre DB et al. Risk stratification for colon neoplasia: screening strategies using colonoscopy and computerized tomographic colonography. Gastroenterology 2006; 131: 1011-1019.

22. Muller AD, Sonnenberg A. Protection by endoscopy against death from colorectal cancer. A case-control study among veterans. Arch Intern Med 1995; 155: 1741-1748.

23. Winawer SJ, Stewart ET, Zauber AG et al. A comparison of colonoscopy and double-contrast barium enema for surveillance after polypectomy. National Polyp Study Work Group. N Engl J Med 2000; 342: 1766-1772.

24. Rex DK, Rahmani EY, Haseman JH et al. Relative sensitivity of colonoscopy and barium enema for detection of colorectal cancer in clinical practice. Gastroenterology 1997; 112: 17-23.

25. Pickhardt PJ, Choi JR, Hwang I et al. Computed tomographic virtual colonoscopy to screen for colorectal neoplasia in asymptomatic adults. $\mathrm{N}$ Engl J Med 2003; 349: 2191-2200.

26. Stoop EM, de Haan MC, de Wijkerslooth TR et al. Participation and yield of colonoscopy versus non-cathartic CT colonography in population-based screening for colorectal cancer: a randomised controlled trial. Lancet Oncol 2012; 13: 55-64.

27. Rosman AS, Korsten MA. Meta-analysis comparing CT colonography, air contrast barium enema, and colonoscopy. Am J Med 2007; 120: 203-210. e4.

28. Perisinakis K, Seimenis I, Tzedakis A et al. Screening computed tomography colonography with 256-slice scanning: should patient radiation burden and associated cancer risk constitute a major concern? Invest Radiol 2012; 47: 451-456.

29. Schoen RE, Pinsky PF, Weissfeld JL et al. Colorectal-cancer incidence and mortality with screening flexible sigmoidoscopy. N Engl J Med 2012; 366: 2345-2357.

30. Adler A, Wegscheider K, Lieberman D et al. Factors determining the quality of screening colonoscopy: a prospective study on adenoma detection rates, from 12134 examinations (Berlin colonoscopy project 3, BECOP-3). Gut 2012.

31. Nissan A, Stojadinovic A, Mitrani-Rosenbaum S et al. Colon cancer associated transcript-1: a novel RNA expressed in malignant and pre-malignant human tissues. Int J Cancer 2012; 130: 1598-1606.

32. Arlen M, Tsang A, Wang T. Immunotherapy of colon cancer using chimeric mAb 31.1. Crit Rev Immunol 1998; 18: 133-138.

33. Arlen M, Wang X, Luka J et al. The use of specific monoclonal antibodies to target immunogenic tumor membrane proteins in patients with recurrent pancreatic and colon cancer. Curr Drug Deliv 2012; 9: 52-56.

34. Damania D, Roy HK, Subramanian H et al. Nanocytology of rectal colonocytes to assess risk of colon cancer based on field cancerization. Cancer Res 2012; 72: 2720-2727.

35. He J, Evers DL, O'Leary TJ, Mason JT. Immunoliposome-PCR: a generic ultrasensitive quantitative antigen detection system. J Nanobiotechnology 2012; 10: 26.

36. Pucci S, Bonanno E, Sesti F et al. Clusterin in stool: a new biomarker for colon cancer screening? Am J Gastroenterol 2009; 104: 2807-2815.

37. Di Marzio L, Di Leo A, Cinque B et al. Detection of alkaline sphingomyelinase activity in human stool: proposed role as a new diagnostic and prognostic marker of colorectal cancer. Cancer Epidemiol Biomarkers Prev 2005; 14: 856-862.

38. Corte H, Manceau G, Blons H, Laurent-Puig P. MicroRNA and colorectal cancer. Dig Liver Dis 2012; 44: 195-200.

39. Berger BM, Ahlquist DA. Stool DNA screening for colorectal neoplasia: biological and technical basis for high detection rates. Pathology 2012; 44: 80-88.

40. Freeman HJ. Crypt region localization of intestinal stem cells in adults. World J Gastroenterol 2008; 14: 7160-7162.

41. Dhawan P, Ahmad R, Srivastava AS, Singh AB. Cancer stem cells and colorectal cancer: an overview. Curr Top Med Chem 2011; 11: 1592-1598.
42. Buczacki S, Davies RJ, Winton DJ. Stem cells, quiescence and rectal carcinoma: an unexplored relationship and potential therapeutic target. Br J Cancer 2011; 105: 1253-1259.

43. Rizk P, Barker N. Gut stem cells in tissue renewal and disease: methods, markers, and myths. Wiley Interdiscip Rev Syst Biol Med 2012; 4: 475-496.

44. Draht MX, Riedl RR, Niessen $\mathrm{H}$ et al. Promoter CpG island methylation markers in colorectal cancer: the road ahead. Epigenomics 2012; 4: 179-194.

45. Kim MS, Lee J, Sidransky D. DNA methylation markers in colorectal cancer. Cancer Metastasis Rev 2010; 29: 181-206.

46. Patai AV, Molnar B, Kalmar A et al. Role of DNA methylation in colorectal carcinogenesis. Dig Dis 2012; 30: 310-315.

47. Luo YX, Chen DK, Song SX et al. Aberrant methylation of genes in stool samples as diagnostic biomarkers for colorectal cancer or adenomas: a meta-analysis. Int J Clin Pract 2011; 65: 1313-1320.

48. Cappell MS. From colonic polyps to colon cancer: pathophysiology, clinical presentation, screening and colonoscopic therapy. Minerva Gastroenterol Dietol 2007; 53: 351-373.

49. Jenkinson F, Steele RJ. Colorectal cancer screening - methodology. Surgeon 2010; 8: 164-171.

50. Wang JY, Hsieh JS, Chang MY et al. Molecular detection of APC, K- ras, and p53 mutations in the serum of colorectal cancer patients as circulating biomarkers. World J Surg 2004; 28: 721-726.

51. Minarik M, Minarikova L, Hrabikova M et al. Application of cycling gradient capillary electrophoresis to detection of APC, K-ras, and DCC point mutations in patients with sporadic colorectal tumors. Electrophoresis 2004; 25: 1016-1021.

52. Pedersen JW, Gentry-Maharaj A, Fourkala EO et al. Early detection of cancer in the general population: a blinded case-control study of p53 autoantibodies in colorectal cancer. Br J Cancer 2012.

53. Jang SH, Min KW, Paik SS, Jang KS. Loss of SIRT1 histone deacetylase expression associates with tumour progression in colorectal adenocarcinoma. J Clin Pathol 2012; 65: 735-739.

54. Donigan KA, Sun KW, Nemec AA et al. Human POLB gene is mutated in high percentage of colorectal tumors. J Biol Chem 2012; 287: 23830-23839.

55. Li BS, Wang XY, Xu AG et al. High-Resolution Melting Assay (HRMA) is a Simple and Sensitive Stool-Based DNA Test for the Detection of Mutations in Colorectal Neoplasms. Clin Colorectal Cancer 2012; 11: 280-290.

56. Gerges N, Rak J, Jabado N. New technologies for the detection of circulating tumour cells. Br Med Bull 2010; 94: 49-64.

57. Gerges N, Jabado N. Biomarkers in cancer micrometastasis: where are we at? Bioanalysis 2010; 2: 881-899.

58. Mahmoud W, Sukhanova A, Oleinikov V et al. Emerging applications of fluorescent nanocrystals quantum dots for micrometastases detection. Proteomics 2010; 10: 700-716.

59. Smith LE. Fiberoptic colonoscopy: complications of colonoscopy and polypectomy. Dis Colon Rectum 1976; 19: 407-412.

60. Stevenson GW, Wilson JA, Wilkinson J et al. Pain following colonoscopy: elimination with carbon dioxide. Gastrointest Endosc 1992; 38: 564-567.

61. Steine S. Which hurts the most? A comparison of pain rating during double-contrast barium enema examination and colonoscopy. Radiology 1994; 191: 99-101.

62. Orsoni P, Berdah S, Verrier C et al. Colonic perforation due to colonoscopy: a retrospective study of 48 cases. Endoscopy 1997; 29: 160-164.

63. Rickert RR, Auerbach O, Garfinkel L et al. Adenomatous lesions of the large bowel: an autopsy survey. Cancer 1979; 43: 1847-1857.

64. Granqvist S. Distribution of polyps in the large bowel in relation to age. A colonoscopic study. Scand J Gastroenterol 1981; 16: 1025-1031.

65. Stryker SJ, Wolff BG, Culp CE et al. Natural history of untreated colonic polyps. Gastroenterology 1987; 93: 1009-1013.

66. Bressler B, Paszat LF, Vinden C et al. Colonoscopic miss rates for right-sided colon cancer: a population-based analysis. Gastroenterology 2004; 127: 452-456.

67. Pickhardt PJ, Nugent PA, Mysliwiec PA et al. Location of adenomas missed by optical colonoscopy. Ann Intern Med 2004; 141: 352-359.

68. Heresbach D, Barrioz T, Lapalus MG et al. Miss rate for colorectal neoplastic polyps: a prospective multicenter study of back-to-back video colonoscopies. Endoscopy 2008; 40: 284-290.

69. Johnson CD, Chen MH, Toledano AY et al. Accuracy of CT colonography for detection of large adenomas and cancers. N Engl J Med 2008; 359: 1207-1217.

70. Regge D, Laudi C, Galatola G et al. Diagnostic accuracy of computed tomographic colonography for the detection of advanced neoplasia in individuals at increased risk of colorectal cancer. JAMA 2009; 301: 2453-2461. 
71. Brenner DJ, Hall EJ. Computed tomography--an increasing source of radiation exposure. N Engl J Med 2007; 357: 2277-2284.

72. Wang J, Li T, Lu H, Liang Z. Penalized weighted least-squares approach to sinogram noise reduction and image reconstruction for low-dose X-ray computed tomography. IEEE Trans Med Imaging 2006; 25: 1272-1283.

73. Wang J, Wang S, Li L et al. Virtual Colonoscopy Screening with Ultra Low-Dose CT and Less-Stressful Bowel Preparation: A computer simulation study. IEEE Trans Nucl Sci 2008; 55: 2566-2575.

74. Pappalardo G, Polettini E, Frattaroli FM et al. Magnetic resonance colonography versus conventional colonoscopy for the detection of colonic endoluminal lesions. Gastroenterology 2000; 119: 300-304.

75. Leung E, Ferjani AM, Kitchen A et al. Risk-adjusted scoring systems can predict surgeons' performance in colorectal surgery. Surgeon 2011; 9: 3-7.

76. Freedman AN, Slattery ML, Ballard-Barbash R et al. Colorectal cancer risk prediction tool for white men and women without known susceptibility. J Clin Oncol 2009; 27: 686-693.

77. Colditz GA, Atwood KA, Emmons K et al. Harvard report on cancer prevention volume 4: Harvard Cancer Risk Index. Risk Index Working Group, Harvard Center for Cancer Prevention. Cancer Causes Control 2000; 11: 477-488.

78. Imperiale TF, Wagner DR, Lin CY et al. Using risk for advanced proximal colonic neoplasia to tailor endoscopic screening for colorectal cancer. Ann Intern Med 2003; 139: 959-965.

79. Driver JA, Gaziano JM, Gelber RP et al. Development of a risk score for colorectal cancer in men. Am J Med 2007; 120: 257-263.

80. Zeestraten EC, Kuppen PJ, van de Velde CJ, Marijnen CA. Prediction in rectal cancer. Semin Radiat Oncol 2012; 22: 175-183.

81. Win AK, Macinnis RJ, Hopper JL, Jenkins MA. Risk prediction models for colorectal cancer: a review. Cancer Epidemiol Biomarkers Prev 2012; 21: $398-410$

82. Simon MS, Thomson CA, Pettijohn E et al. Racial differences in colorectal cancer incidence and mortality in the Women's Health Initiative. Cancer Epidemiol Biomarkers Prev 2011; 20: 1368-1378.

83. Lieberman DA, Holub JL, Moravec MD et al. Prevalence of colon polyps detected by colonoscopy screening in asymptomatic black and white patients. JAMA 2008; 300: 1417-1422.

84. Shinto E, Tsuda $\mathrm{H}$, Ueno $\mathrm{H}$ et al. Prognostic implication of laminin-5 gamma 2 chain expression in the invasive front of colorectal cancers, disclosed by area-specific four-point tissue microarrays. Lab Invest 2005; 85: 257-266.

85. Kirkland SC, Henderson K. Collagen IV synthesis is restricted to the enteroendocrine pathway during multilineage differentiation of human colorectal epithelial stem cells. J Cell Sci 2001; 114: 2055-2064.

86. Kirkland SC. Type I collagen inhibits differentiation and promotes a stem cell-like phenotype in human colorectal carcinoma cells. Br J Cancer 2009; 101: 320-326.

87. Mauney J, Volloch V. Collagen I matrix contributes to determination of adult human stem cell lineage via differential, structural conformation-specific elicitation of cellular stress response. Matrix Biol 2009; 28: 251-262.

88. Schenke-Layland K, Angelis E, Rhodes KE et al. Collagen IV induces trophoectoderm differentiation of mouse embryonic stem cells. Stem Cells 2007; 25: 1529-1538.

89. Almenoff JS, Williams SI, Scheving LA et al. Ligand-based histochemical localization and capture of cells expressing heat-stable enterotoxin receptors. Mol Microbiol 1993; 8: 865-873.

90. Carrithers SL, Barber MT, Biswas S et al. Guanylyl cyclase C is a selective marker for metastatic colorectal tumors in human extraintestinal tissues. Proc Natl Acad Sci U S A 1996; 93: 14827-14832.

91. Carrithers SL, Parkinson SJ, Goldstein S et al. Escherichia coli heat-stable toxin receptors in human colonic tumors. Gastroenterology 1994; 107: 1653-1661.

92. Cohen MB, Guarino A, Shukla R, Giannella RA. Age-related differences in receptors for Escherichia coli heat-stable enterotoxin in the small and large intestine of children. Gastroenterology 1988; 94: 367-373.

93. Cohen MB, Moyer MS, Luttrell M, Giannella RA. The immature rat small intestine exhibits an increased sensitivity and response to Escherichia coli heat-stable enterotoxin. Pediatr Res 1986; 20: 555-560.

94. Guarino A, Cohen M, Thompson M et al. T84 cell receptor binding and guanyl cyclase activation by Escherichia coli heat-stable toxin. Am J Physiol 1987; 253: G775-780.

95. Guarino A, Cohen MB, Giannella RA. Small and large intestinal guanylate cyclase activity in children: effect of age and stimulation by Escherichia coli heat-stable enterotoxin. Pediatr Res 1987; 21: 551-555.
96. Guarino A, Cohen MB, Overmann G et al. Binding of E. coli heat-stable enterotoxin to rat intestinal brush borders and to basolateral membranes. Dig Dis Sci 1987; 32: 1017-1026.

97. Lucas KA, Pitari GM, Kazerounian S et al. Guanylyl cyclases and signaling by cyclic GMP. Pharmacol Rev 2000; 52: 375-414.

98. Rao MC, Guandalini S, Smith PL, Field M. Mode of action of heat-stable Escherichia coli enterotoxin. Tissue and subcellular specificities and role of cyclic GMP. Biochim Biophys Acta 1980; 632: 35-46.

99. Birbe R, Palazzo JP, Walters R et al. Guanylyl cyclase C is a marker of intestinal metaplasia, dysplasia, and adenocarcinoma of the gastrointestinal tract. Hum Pathol 2005; 36: 170-179.

100. Cagir B, Gelmann A, Park J et al. Guanylyl cyclase C messenger RNA is a biomarker for recurrent stage II colorectal cancer. Ann Intern Med 1999; 131: 805-812.

101. Carrithers SL, Parkinson SJ, Goldstein SD et al. Escherichia coli heat-stable enterotoxin receptors. A novel marker for colorectal tumors. Dis Colon Rectum 1996; 39: 171-181.

102. Frick GS, Pitari GM, Weinberg DS et al. Guanylyl cyclase C: a molecular marker for staging and postoperative surveillance of patients with colorectal cancer. Expert Rev Mol Diagn 2005; 5: 701-713.

103. Gelmann A, Desnoyers R, Cagir B et al. Colorectal cancer staging and adjuvant chemotherapy. Expert Opin Pharmacother 2000; 1: 737-755.

104. Schulz S, Hyslop T, Haaf J et al. A validated quantitative assay to detect occult micrometastases by reverse transcriptase-polymerase chain reaction of guanylyl cyclase $\mathrm{C}$ in patients with colorectal cancer. Clin Cancer Res 2006; 12: 4545-4552.

105. Witek ME, Nielsen K, Walters R et al. The putative tumor suppressor $\mathrm{Cdx} 2$ is overexpressed by human colorectal adenocarcinomas. Clin Cancer Res 2005; 11: 8549-8556.

106. Waldman SA, Hyslop T, Schulz S et al. Association of GUCY2C expression in lymph nodes with time to recurrence and disease-free survival in pN0 colorectal cancer. JAMA 2009; 301: 745-752.

107. Hyslop T, Weinberg D, Barkun A et al. Occult tumor burden predicts chemotherapeutic benefit in pN0 colon cancer. Submitted 2011.

108. Hyslop T, Weinberg DS, Schulz S et al. Occult tumor burden predicts disease recurrence in lymph node-negative colorectal cancer. Clin Cancer Res 2011; 17: 3293-3303.

109. Hyslop T, Weinberg DS, Schulz S et al. Occult tumor burden contributes to racial disparities in stage-specific colorectal cancer outcomes. Cancer 2012 May 1;118(9):2532-40.

110. Hyslop T, Weinberg DS, Schulz S et al. Staging colorectal cancer by occult tumor burden depends on number of lymph nodes analyzed. Submitted 2011.

111. White PM, Sahu M, Poles MA, Francois F. Colorectal cancer screening of high-risk populations: A national survey of physicians. BMC Res Notes 2012; 5: 64

112. Barrison AF, Smith C, Oviedo J et al. Colorectal cancer screening and familial risk: a survey of internal medicine residents' knowledge and practice patterns. Am J Gastroenterol 2003; 98: 1410-1416.

113. Ramsey SD, McDermott CL, Clarke L, Blough DK. Health insurer policies toward risk-stratified colorectal cancer screening: a survey of health plan medical directors. J Insur Med 2012; 43: 92-101.

114. Siegel R, Naishadham D, Jemal A. Cancer statistics, 2012. CA Cancer J Clin 2012; 62: 10-29. 